\title{
Should We Mine the Seafloor?
}

Session for 2017 AAAS Annual Meeting (February 16-20, 2017)

\author{
Speakers: \\ Dr. Thomas Graedel (Yale) \\ Dr. Mark Hannington (GEOMAR) \\ Dr. Stace Beaulieu (WHOI)
}

Moderator: Mindy Todd (WCAI, The Cape \& Islands NPR Station) 


\title{
Dr. Thomas Graedel (Yale) Evolving Metal Demands May Challenge Land-Based Supplies
}

https://aaas.confex.com/aaas/2017/webprogram/Paper18980.html

\author{
Dr. Mark Hannington (GEOMAR) \\ Prospects for Deep-Sea Mining
}

https://aaas.confex.com/aaas/2017/webprogram/Paper18995.html

\section{Dr. Stace Beaulieu (WHOI) Ecosystem Services from the Deep Sea}

https://aaas.confex.com/aaas/2017/webprogram/Paper18994.html 


\title{
Evolving Metal Demands May Challenge Land-Based Supplies
}

\author{
Thomas E. Graedel \\ Yale University
}

Should We Mine the Seafloor?

AAAS 2017 Annual Meeting, February 18, 2017 


\section{Why consider deep-sea mining?}

- Land-based mining has significant ecosystem interactions

- Many people would just like to stop landbased mining

- Land-based mining resources may be insufficient to meet future demands 


\section{Ecosystem interactions of land-based mining}




\section{Problems from abandoned mines}

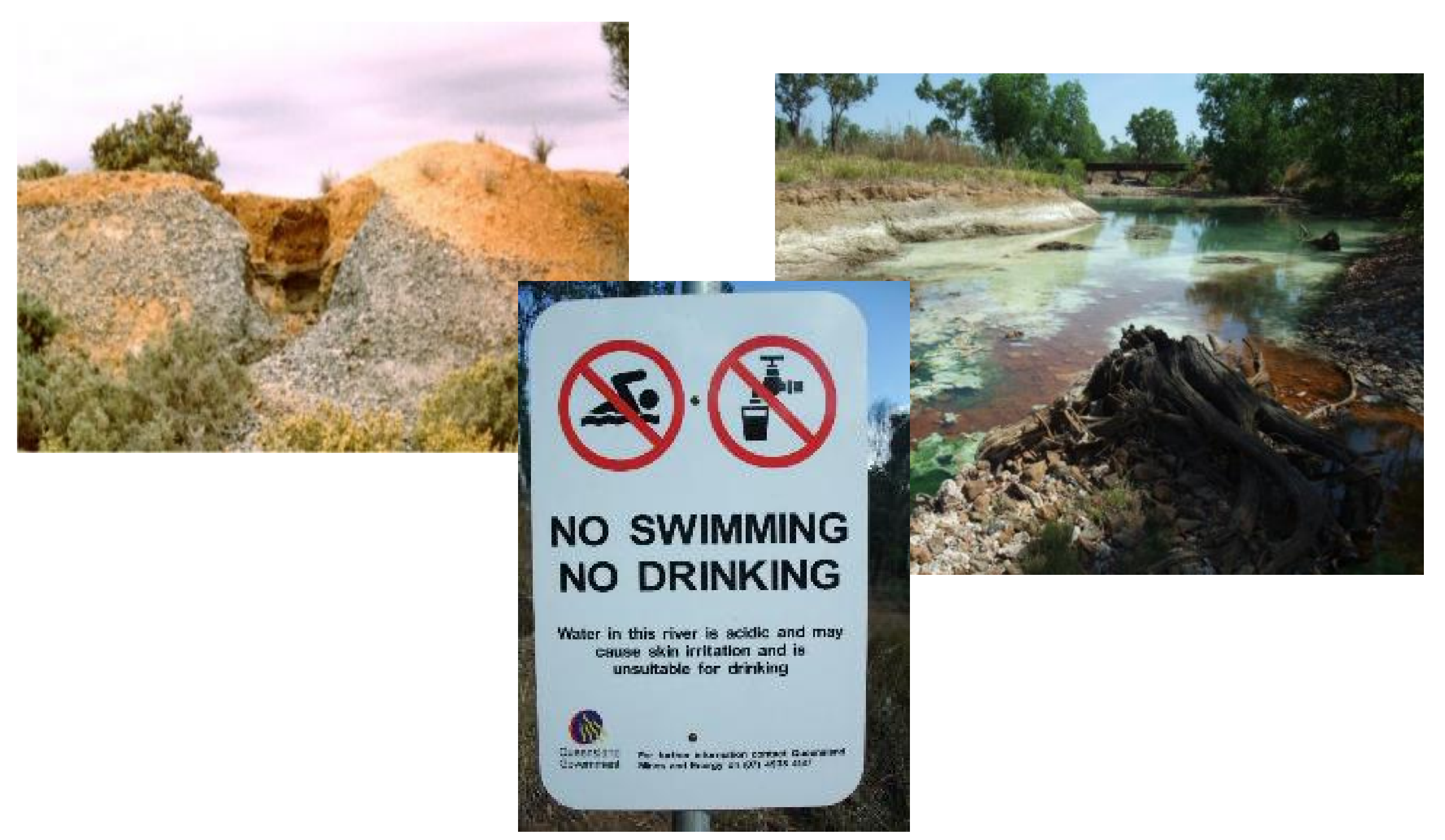


Kolantar, Hungary Tailings Dam Breach, 2010

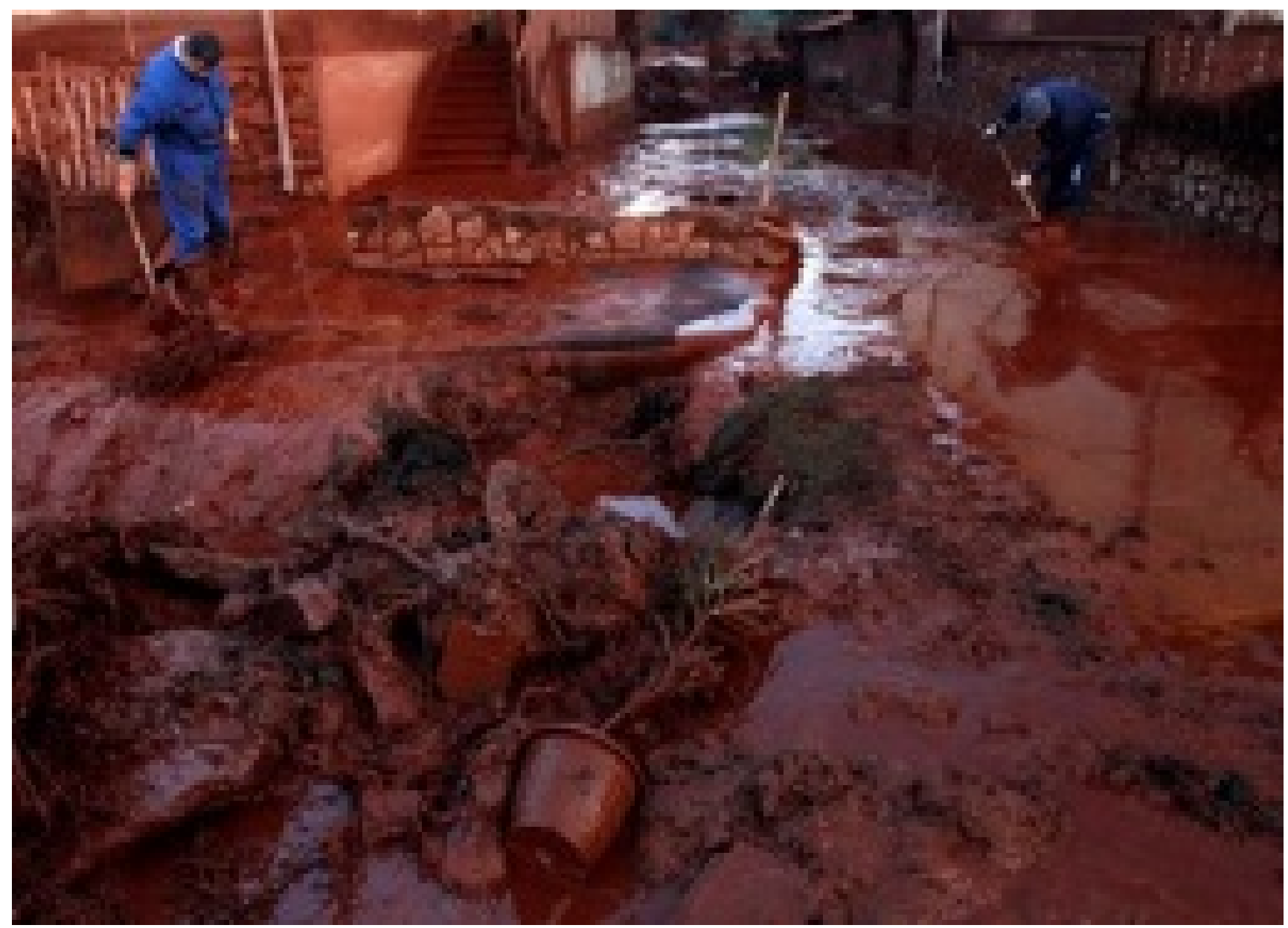




\section{Grizzly Gulch, South Dakota: A stable tailings pond}

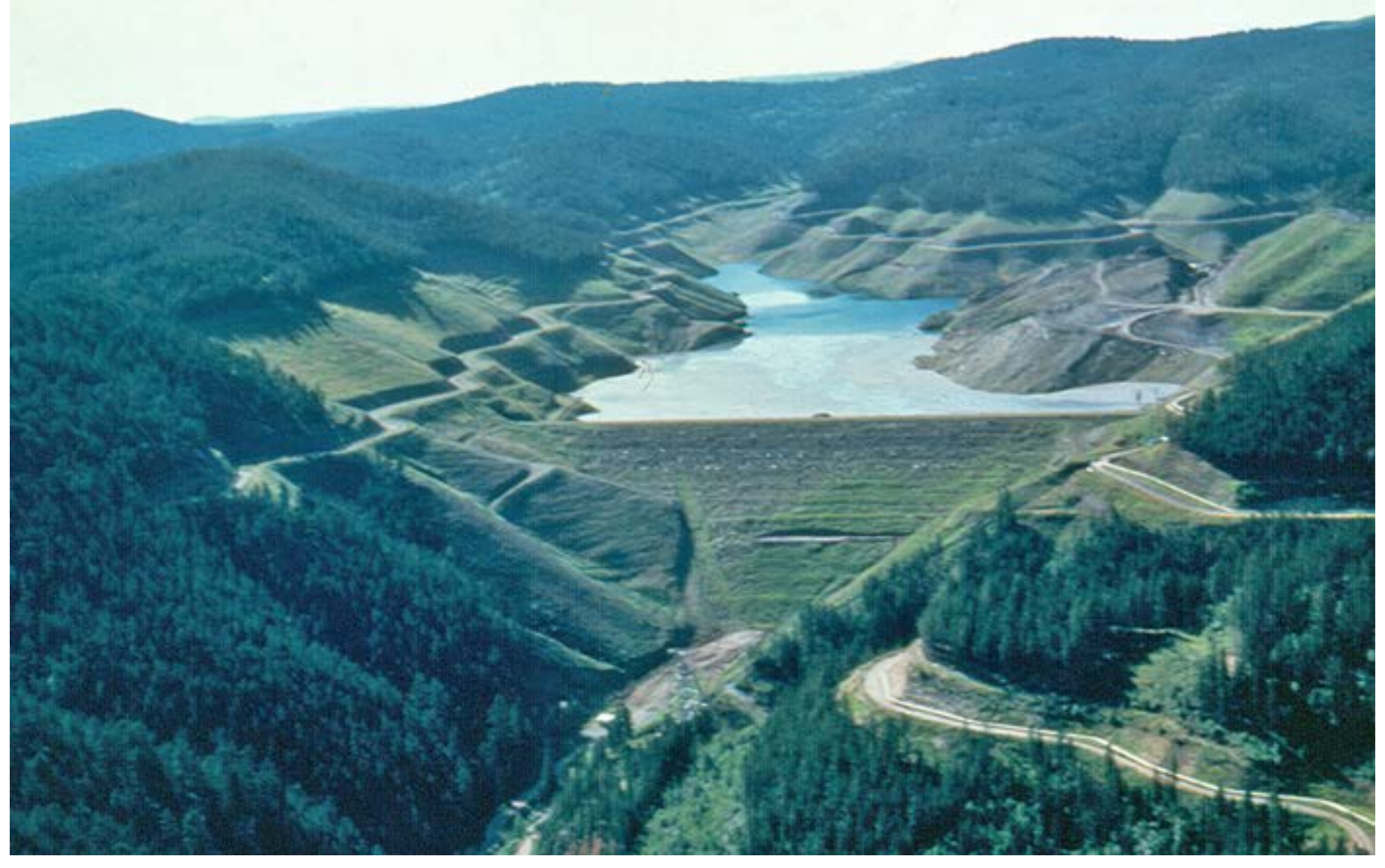


Why do mining at all? 


\section{We all know that if you want this -}

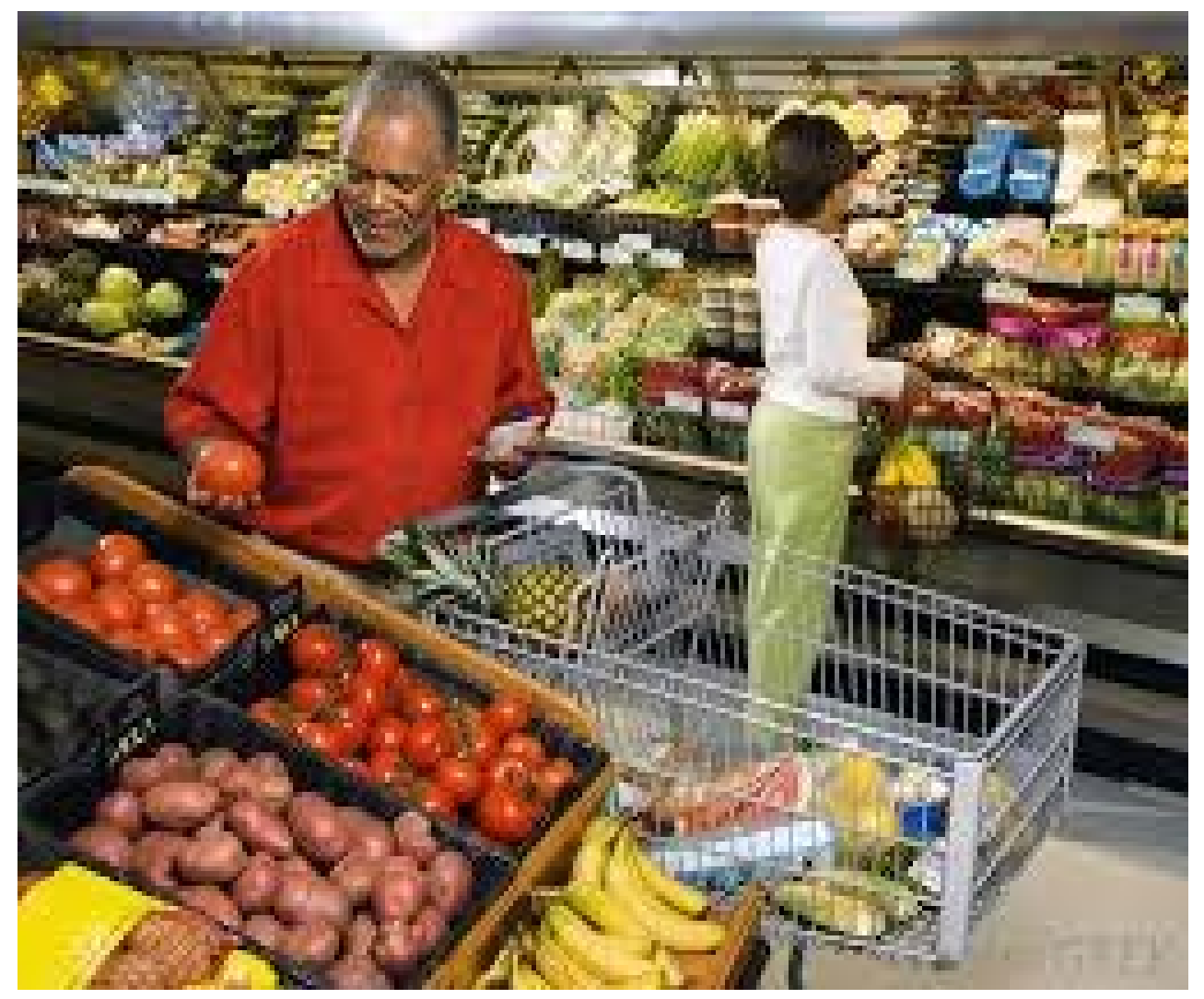




\section{You need this}
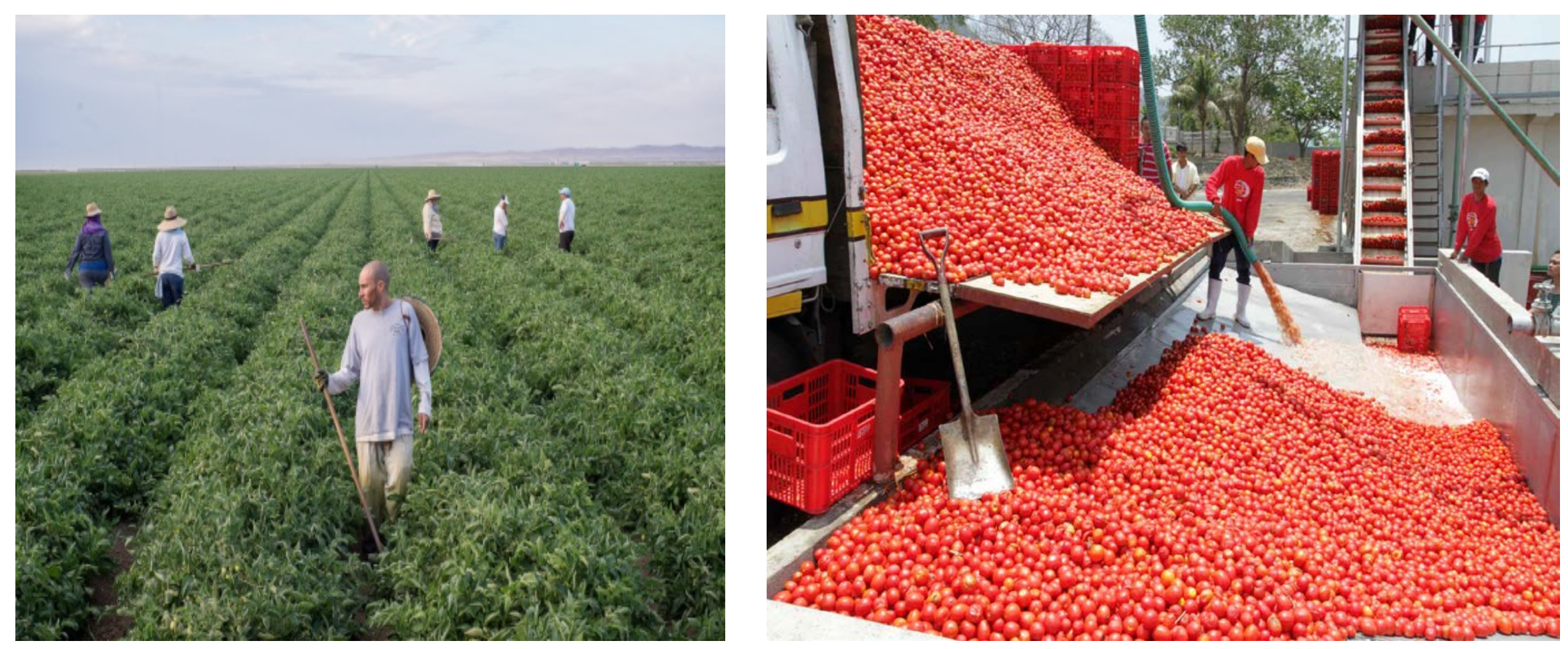


\section{Similarly, if you want this -}
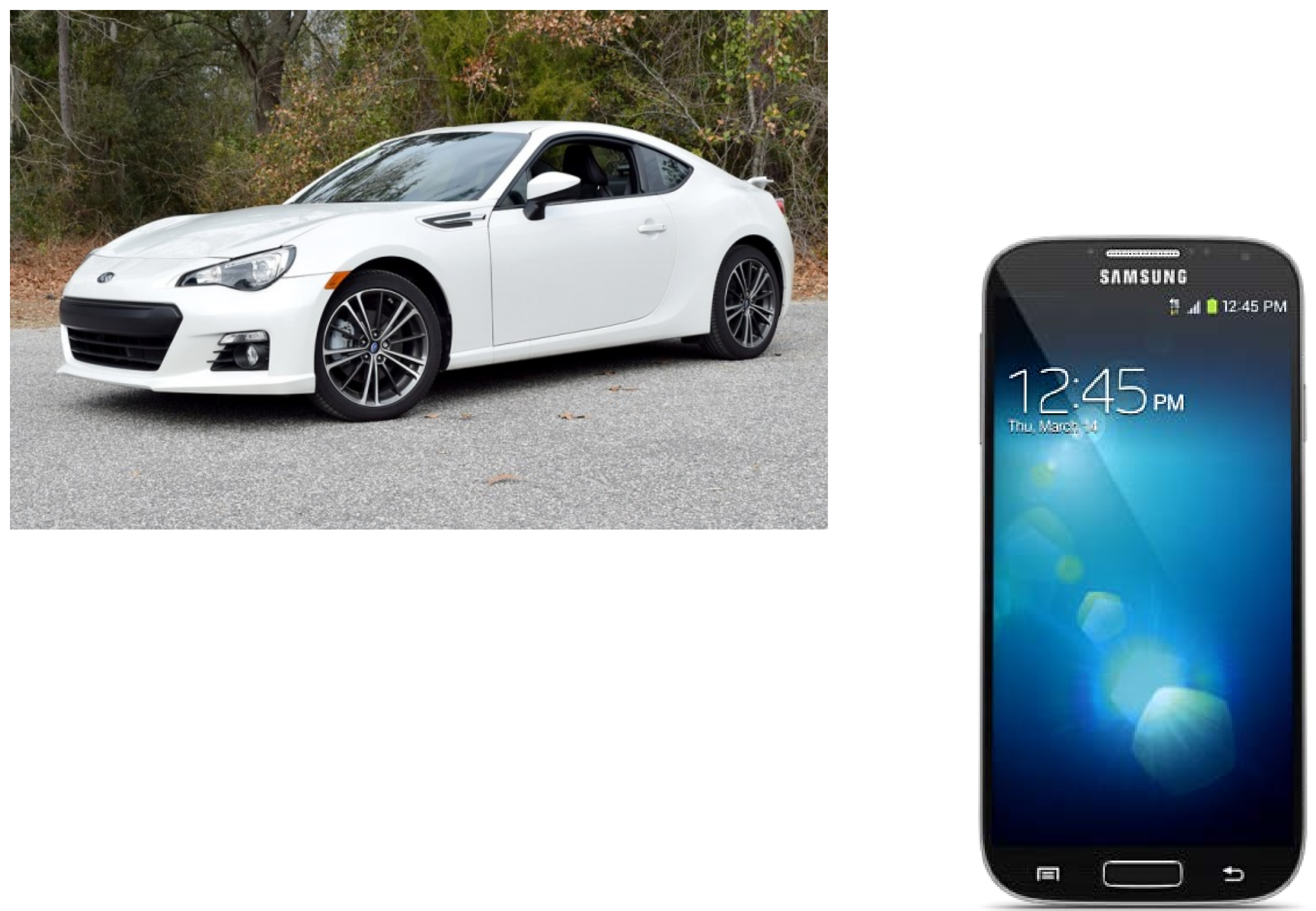


\section{You need this}
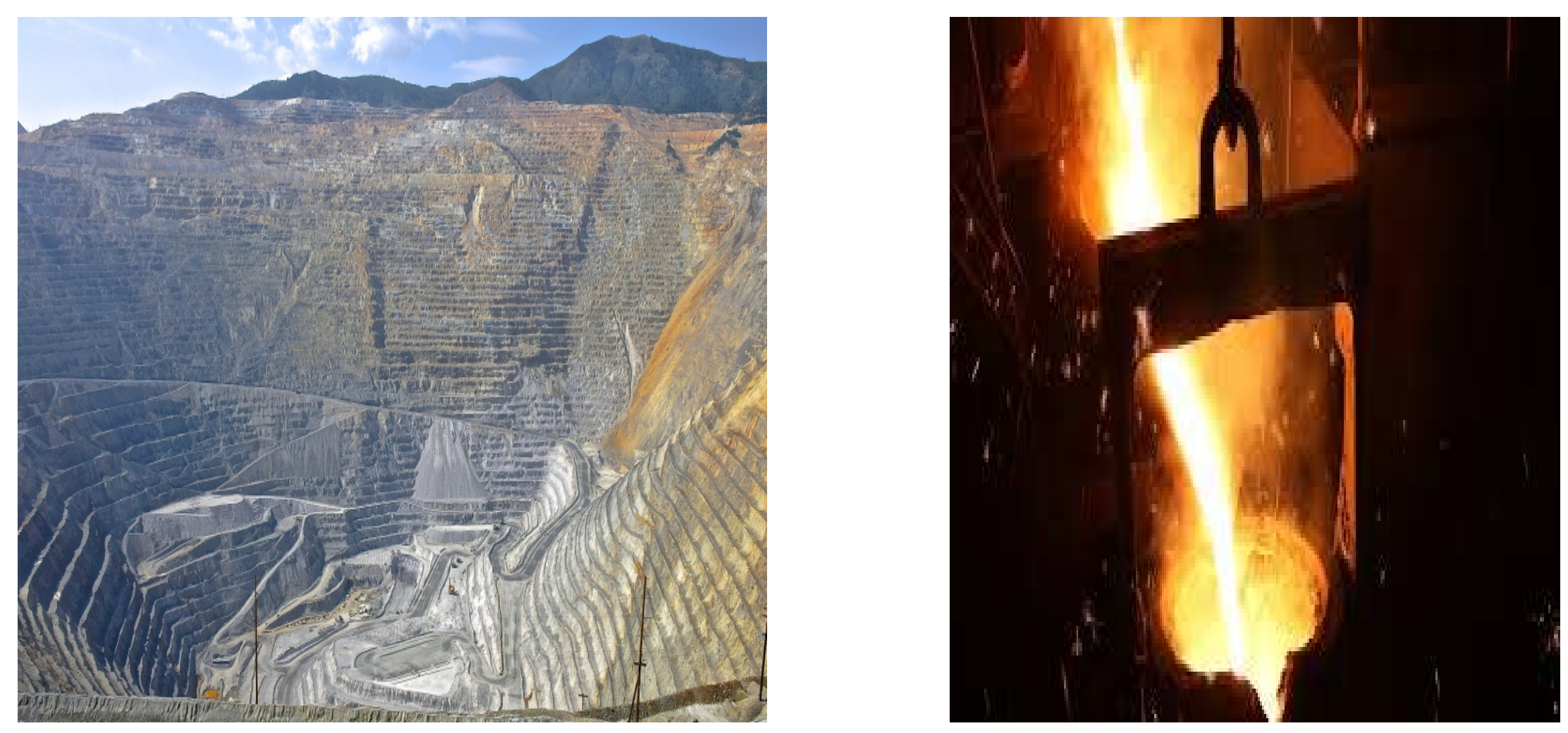

Bingham Canyon, Arizona 
Demand and supply in the future 


\section{Alternative Development Scenarios}

- Market World (MW) - Characterized by strong economic investment and expanded trade

- Toward Resilience (TR) - Centralized policies promote green energy and new infrastructure

- Security Foremost (SF) - A world of disparities, border control, and military focus

- Equitability World (EW) - New paradigms lead to more equitable values and institutions 


\section{Population in the Scenarios}

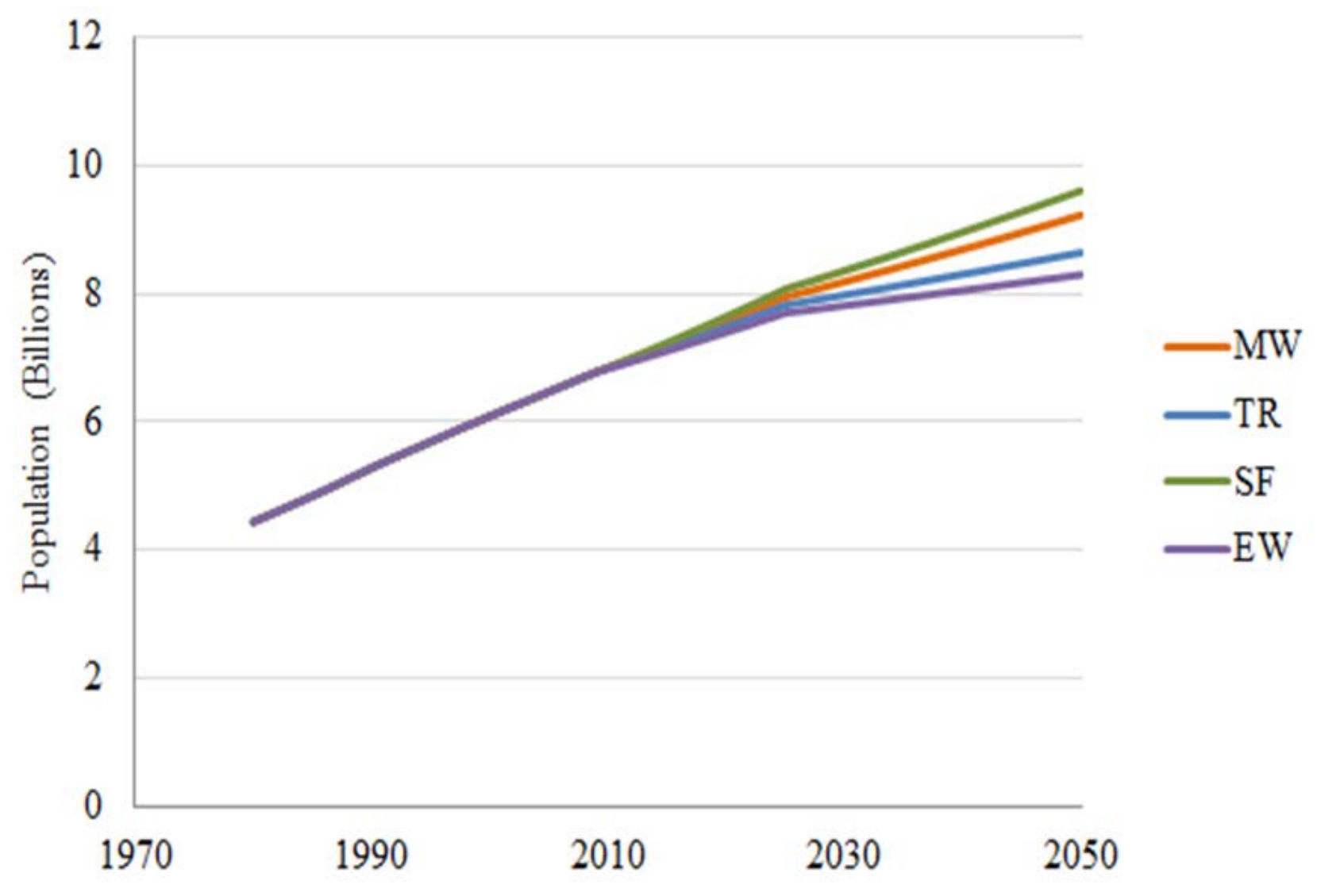




\section{Per Capita Income in the Scenarios}

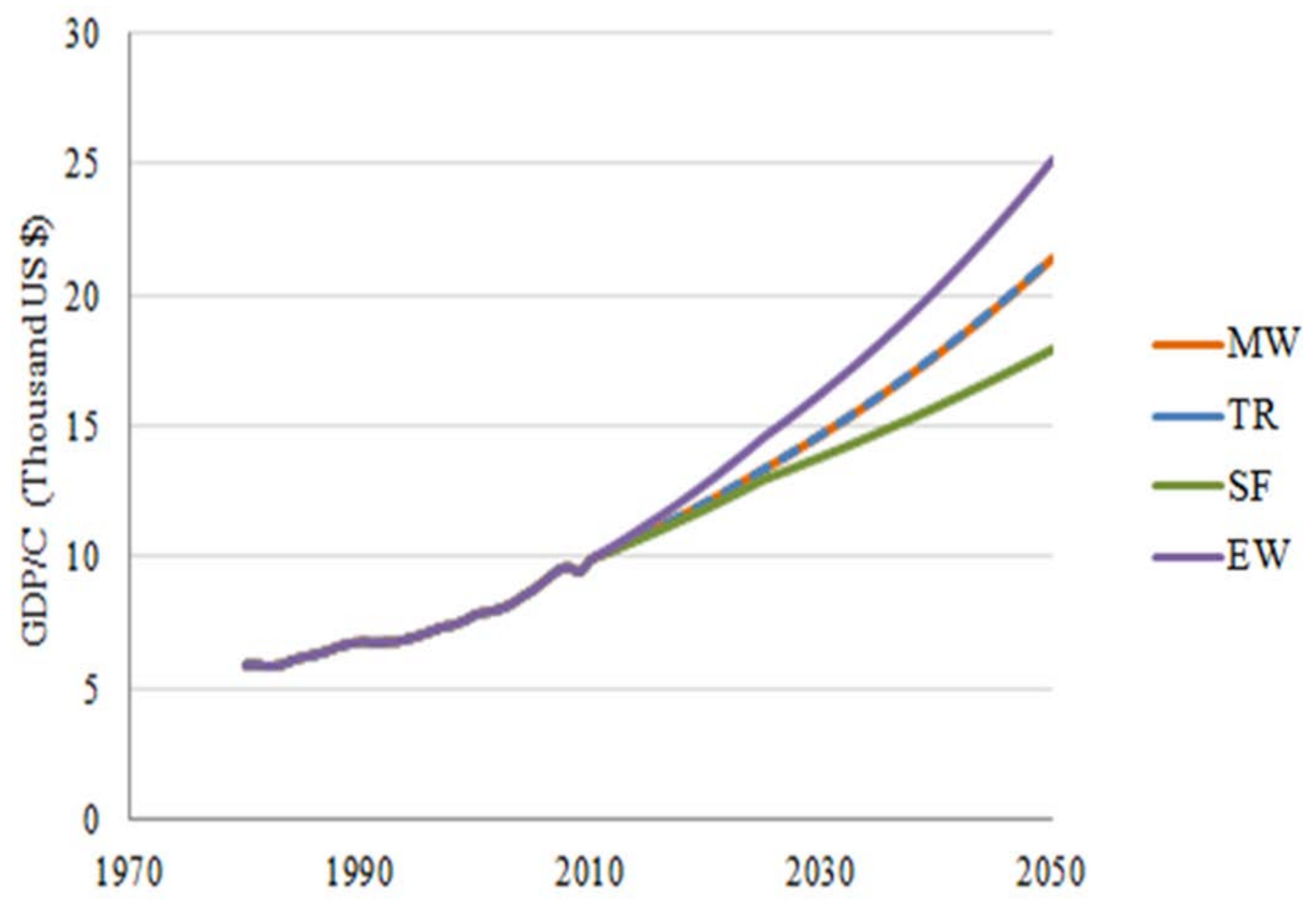




\section{Historical copper use in different industrial sectors}

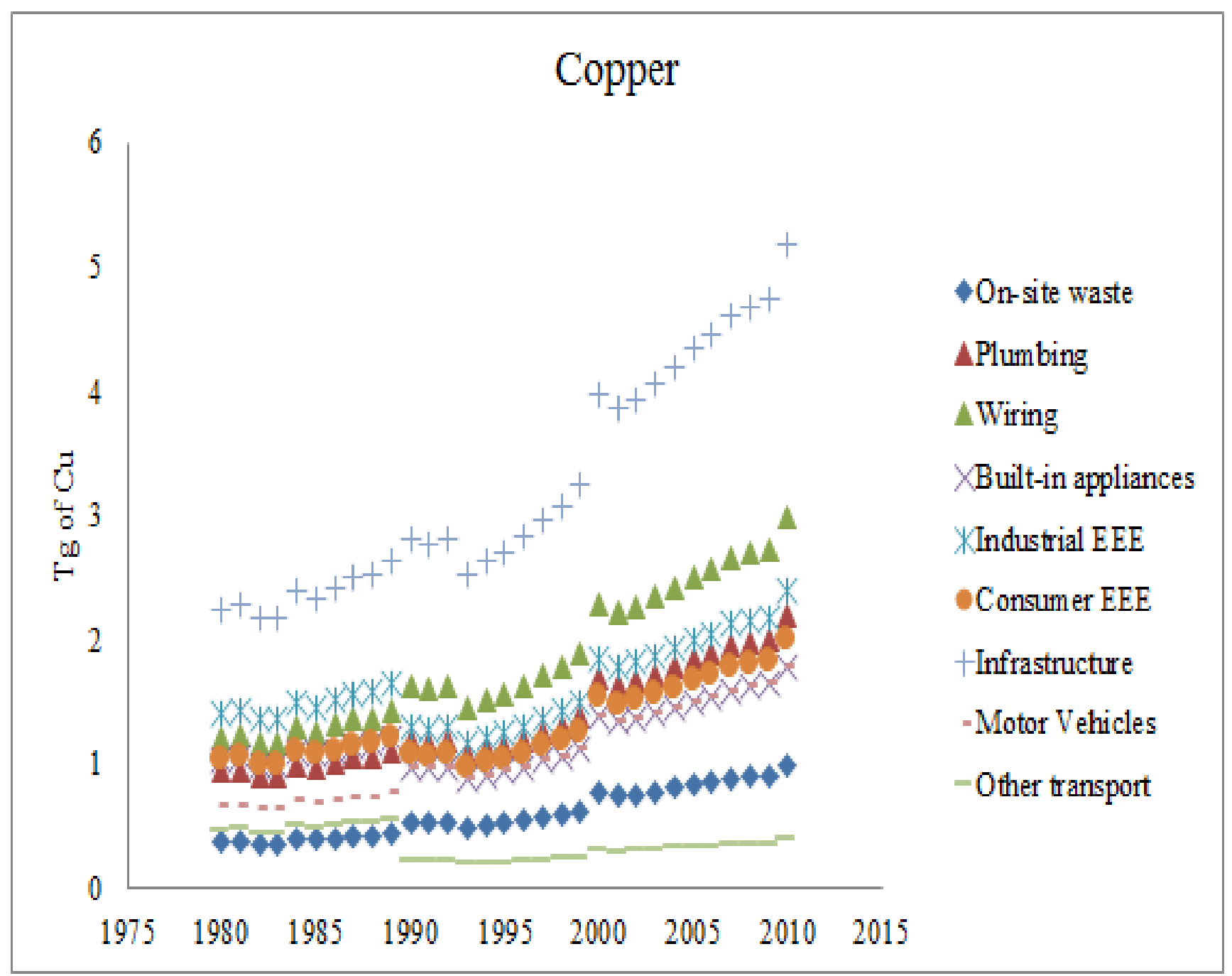




\section{Copper Demand in the Four Scenarios}

(Demand in Tg i.e., million metric tons)

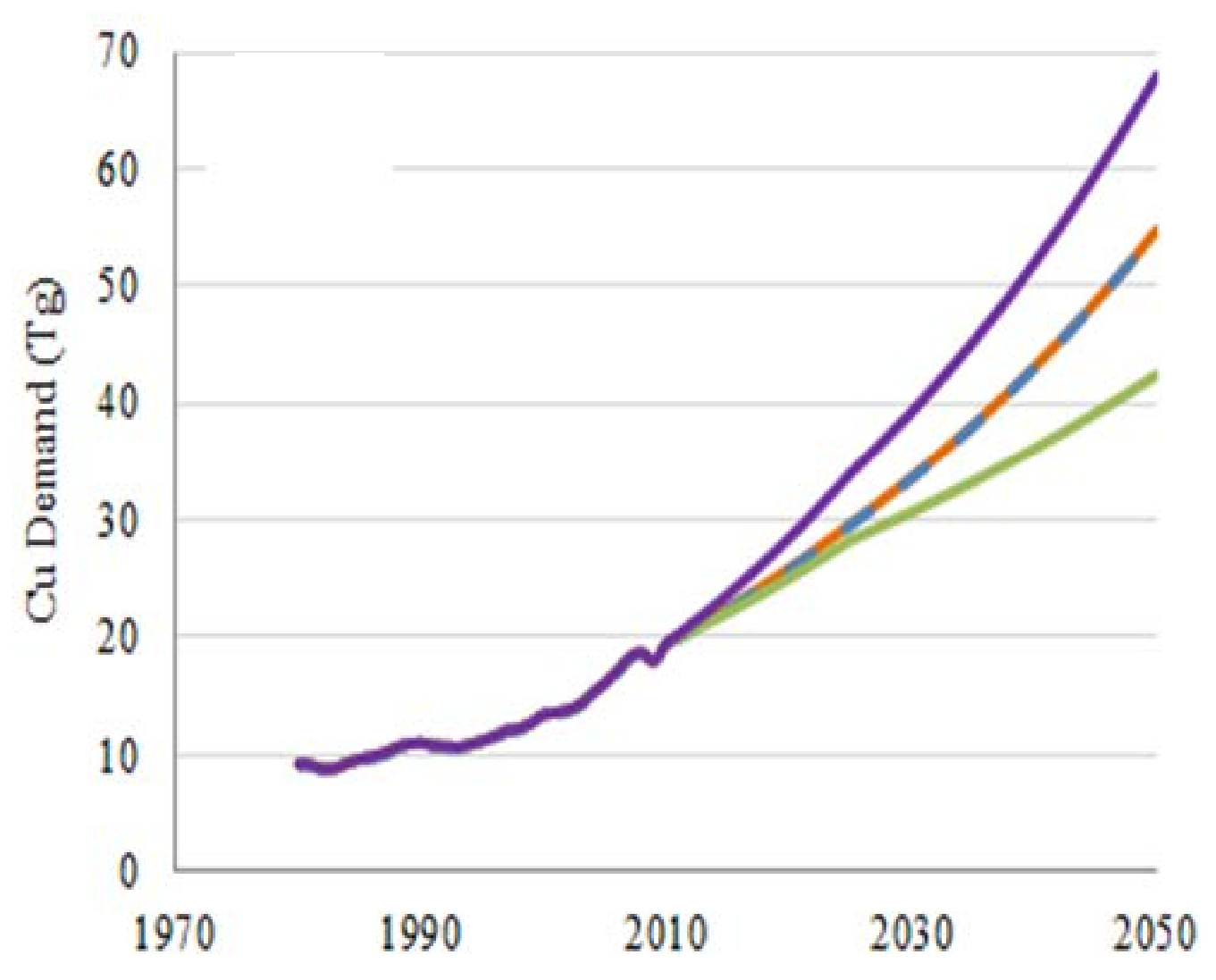




\section{Sectoral demand for copper in the four scenarios}

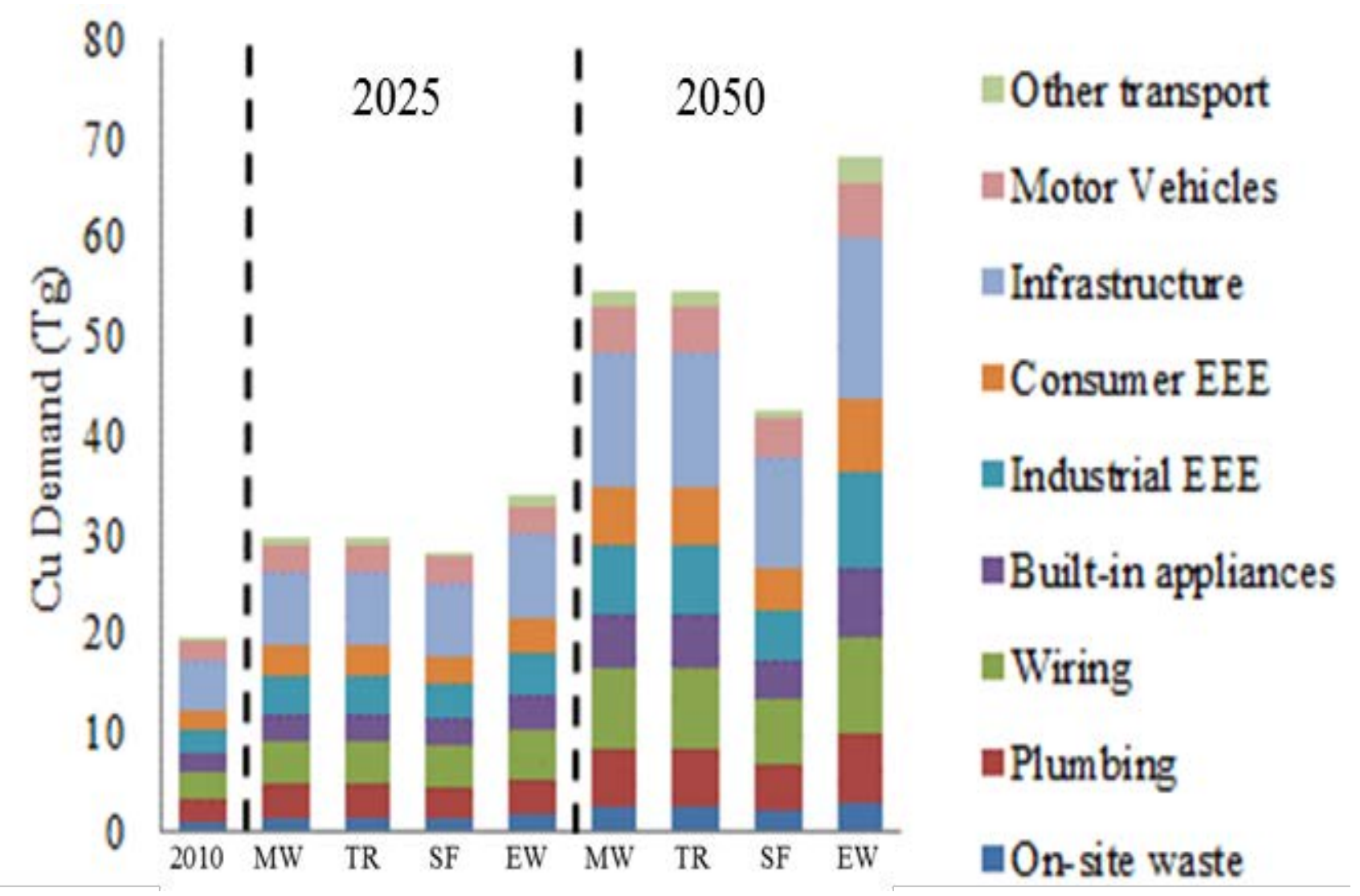


The Anticipated Depletion of Copper Mine Reserves

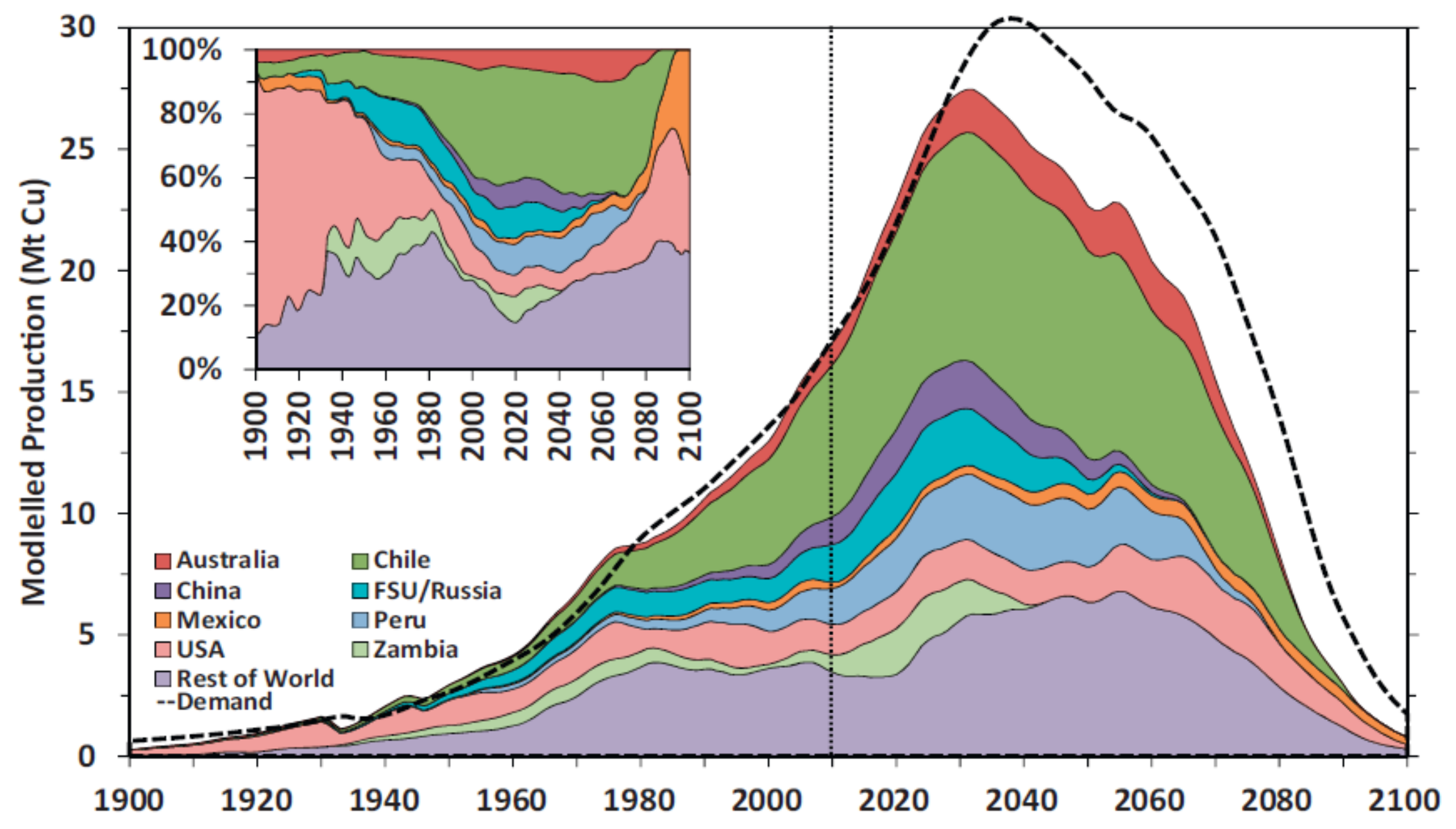

Source: S. Northey et al., Resources, Conservation, \& Recycling, 83, 190-201, 2014 


\section{Summary Comments}

- Land-based mining is of environmental concern (but so is seafloor mining, of course)

- Mining is essential to modern life, but few people realize it

- If global development proceeds at its historic pace, traditional land-based supplies of resources may be challenged to meet demand

- Should we mine the seafloor? In these talks, we provide information for your own decisions 


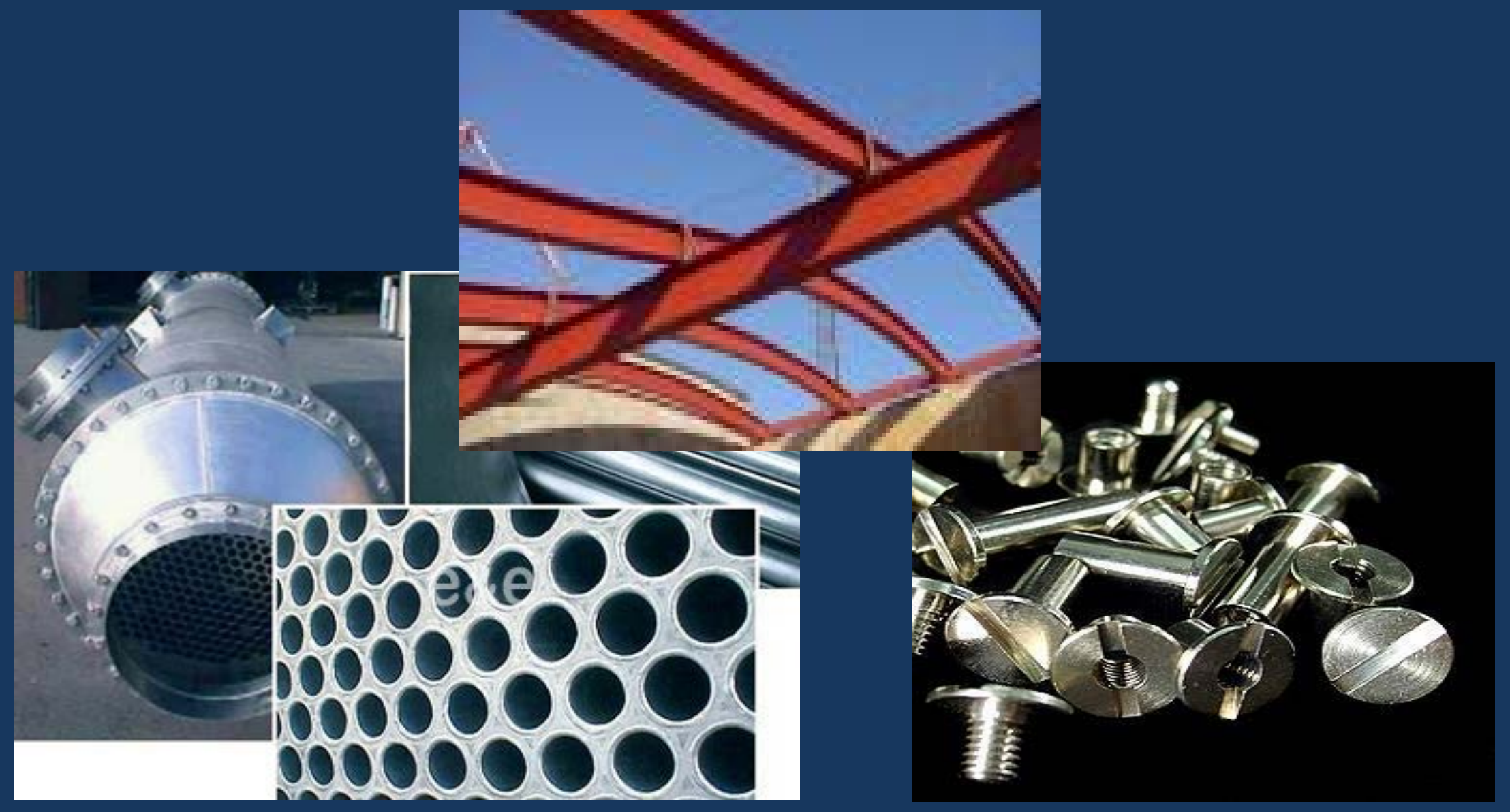

Should We Mine the Seafloor?

AAAS 2017 Annual Meeting, February 18, 2017 


\title{
Prospects for Deep-Sea Mining
}

\author{
Mark Hannington \\ GEOMAR - Helmholtz Center for Ocean Research Kiel \\ mhannington@geomar.de
}

Should We Mine the Seafloor?

AAAS 2017 Annual Meeting, February 18, 2017 


\section{What is deep-sea mining?}

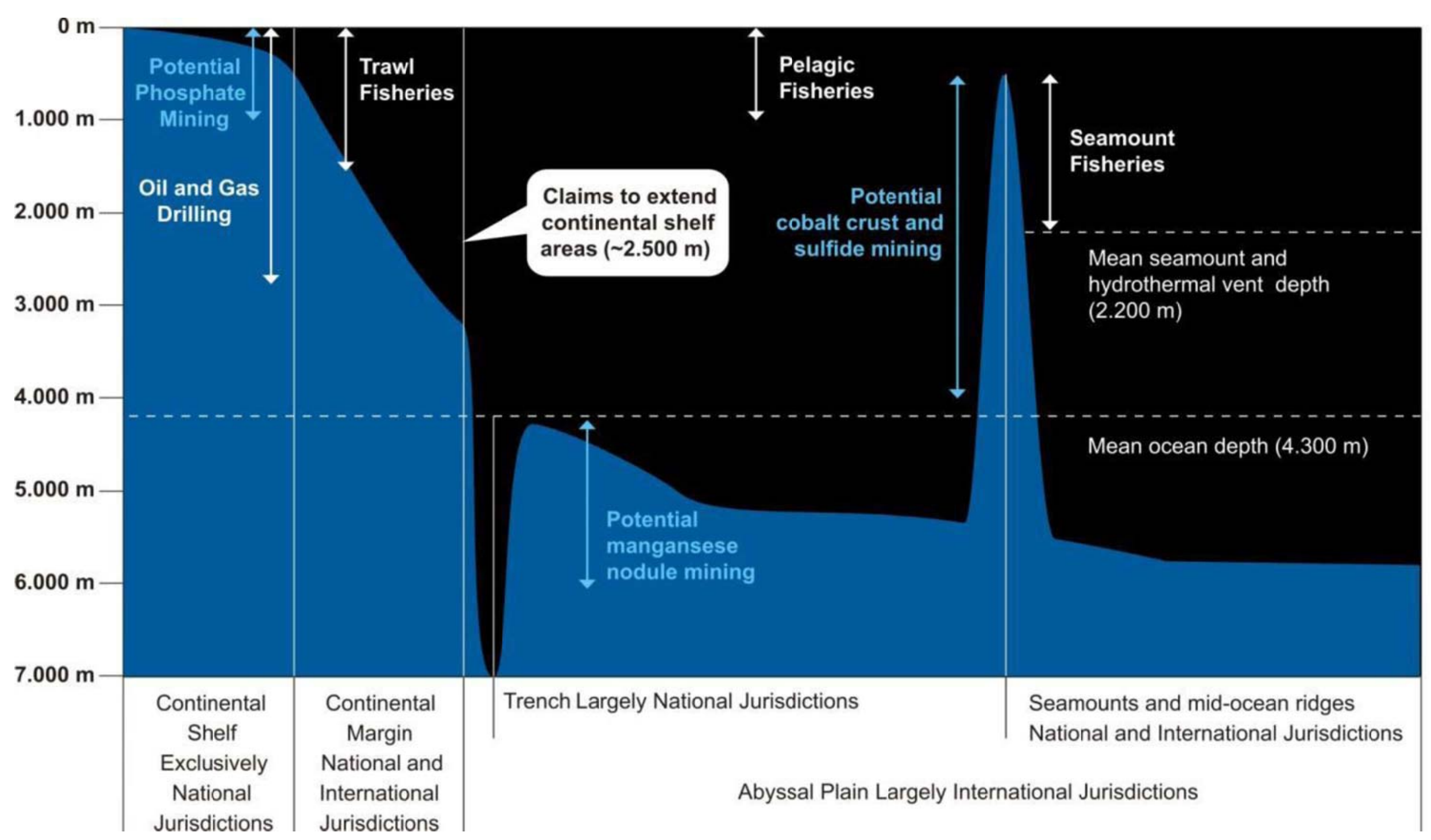




\section{What is deep-sea mining?}

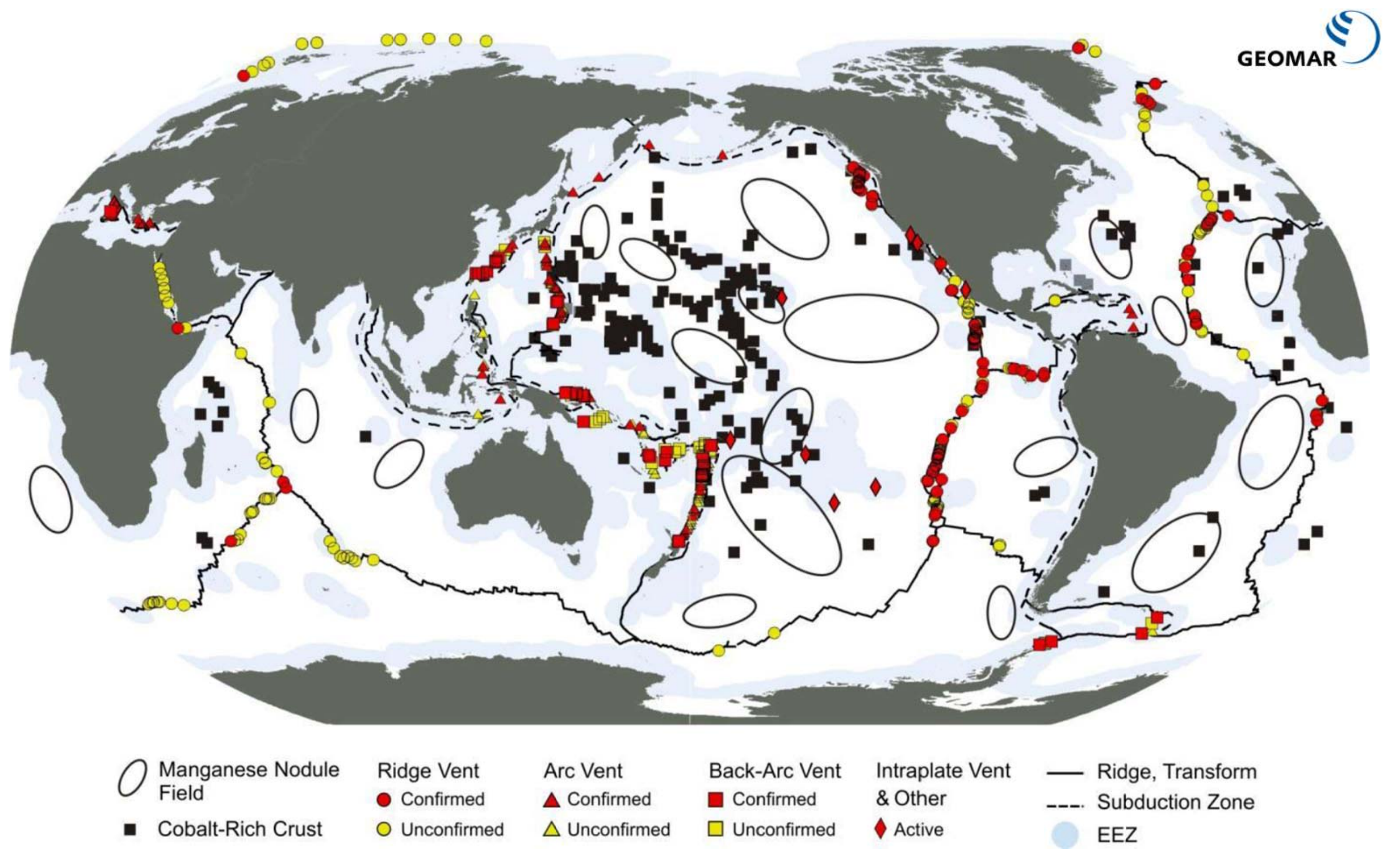




\section{Billion tonnes}

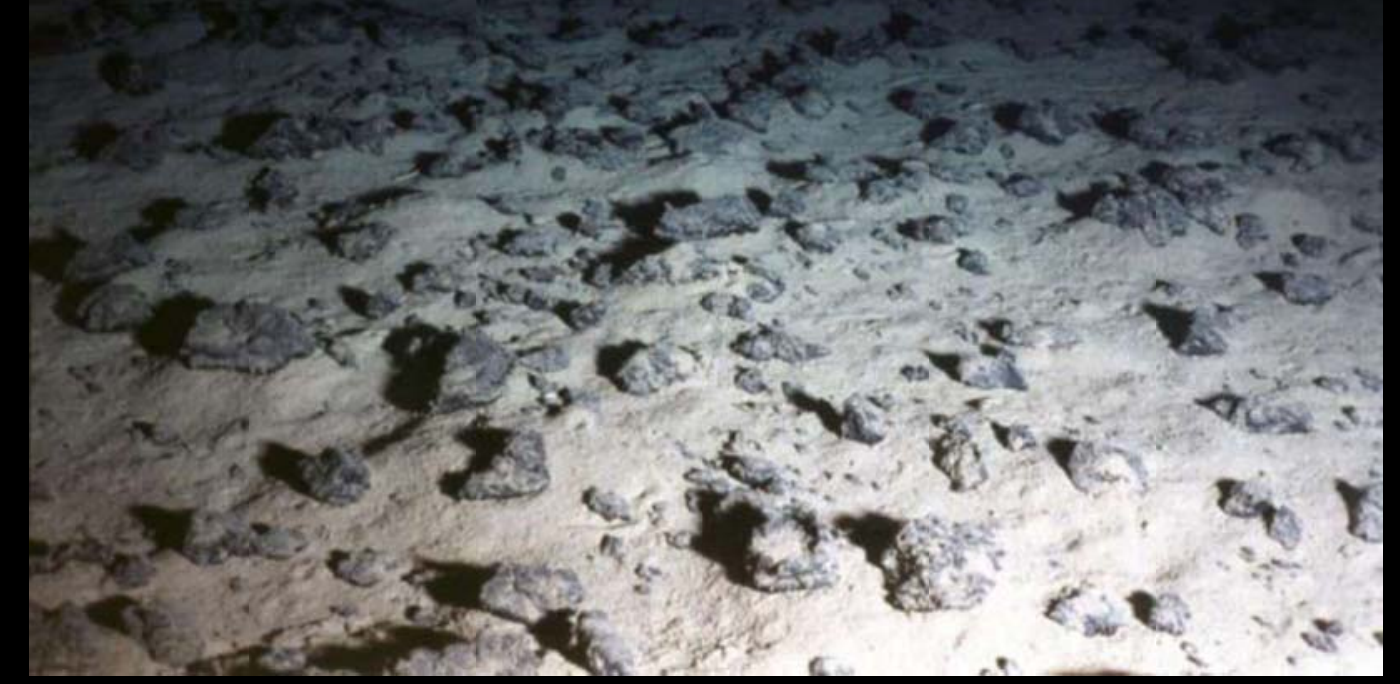

7,500 million tonnes $\mathrm{Mn}$ 256 million tonnes $\mathrm{Cu}$ 340 million tonnes $\mathrm{Ni}$ 78 million tonnes Co 


\section{Loose and round ... hard and smooth}

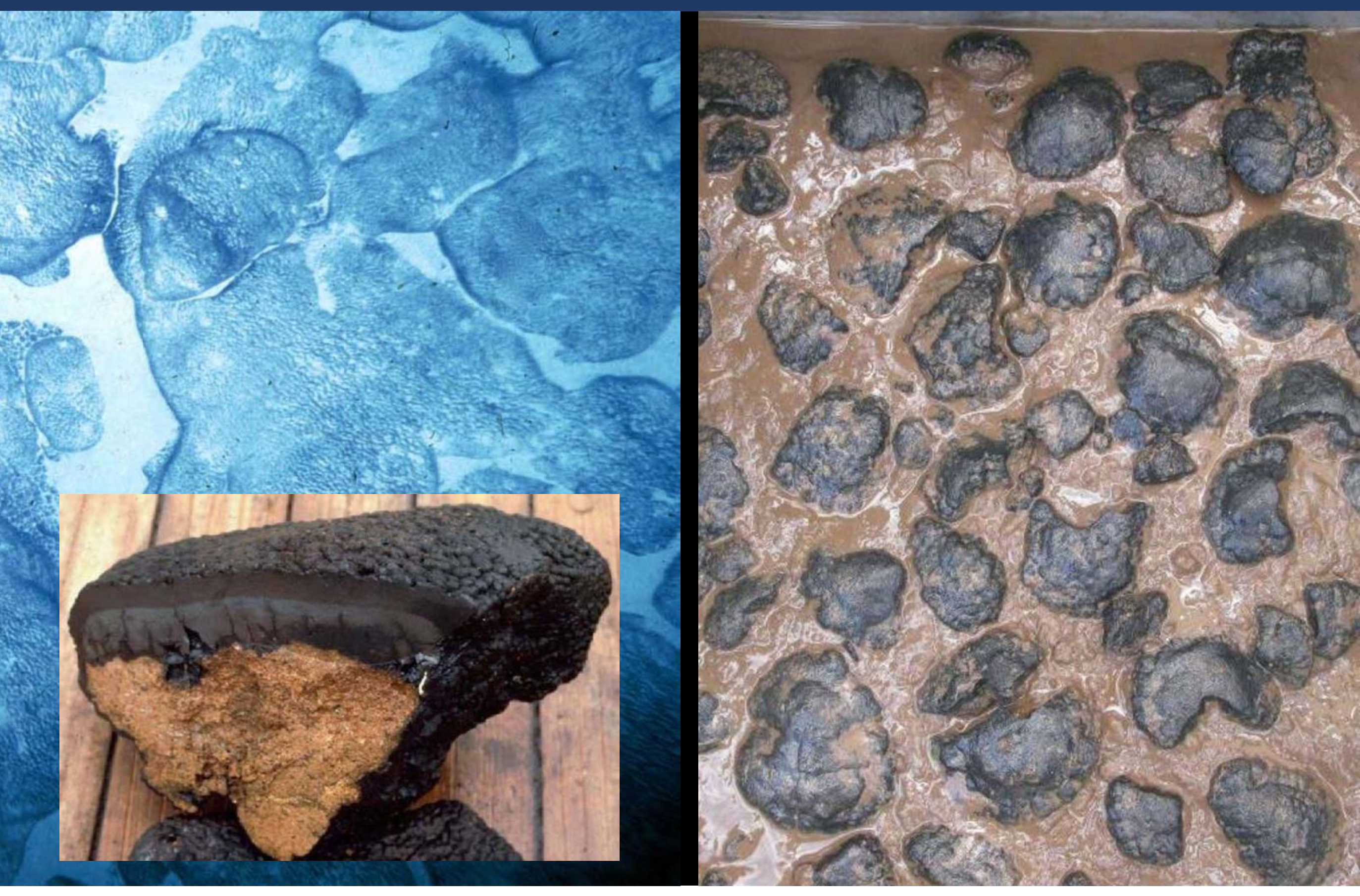




\section{Quality versus quantity?}
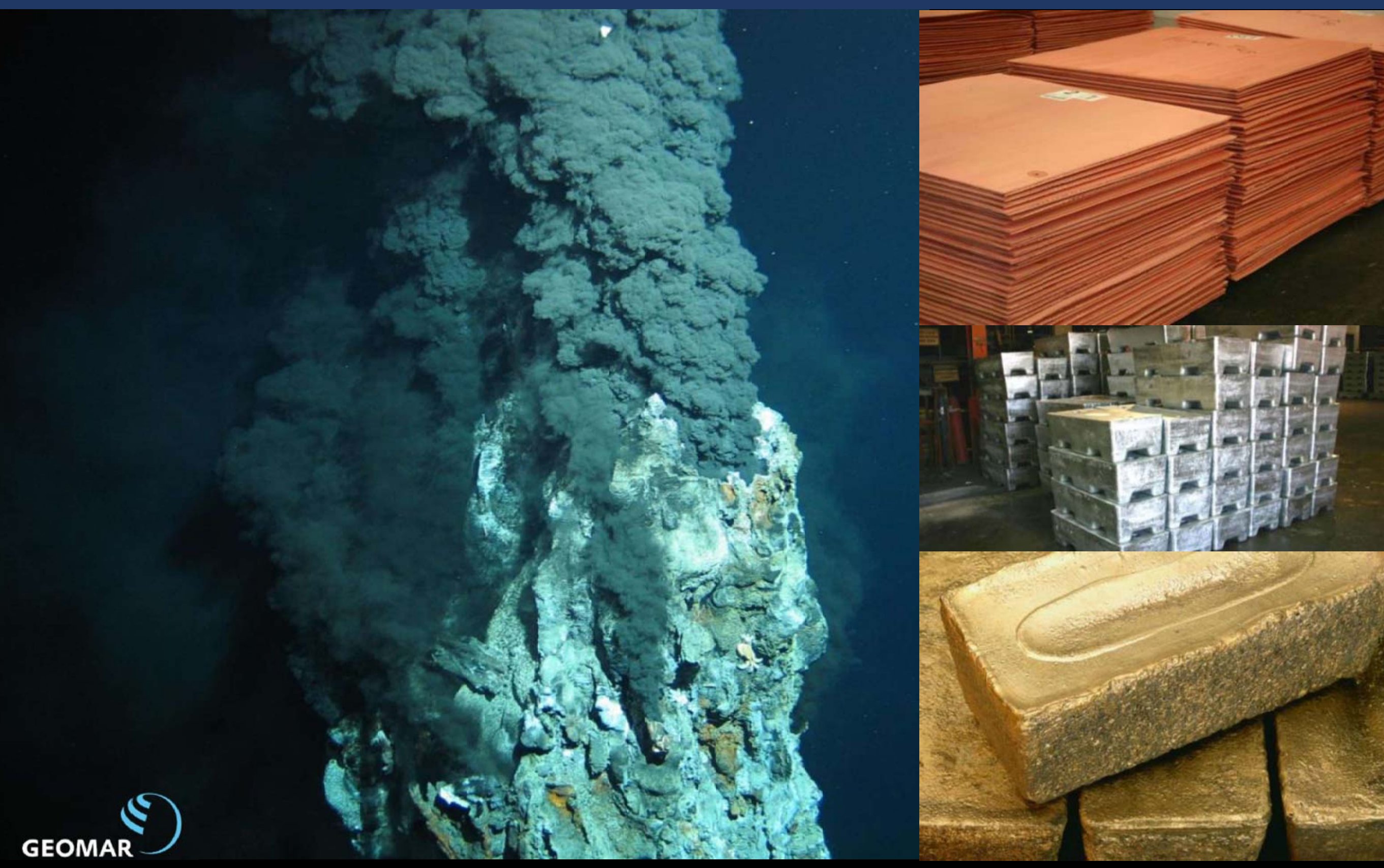


\section{Can deep-sea mining make a difference?}

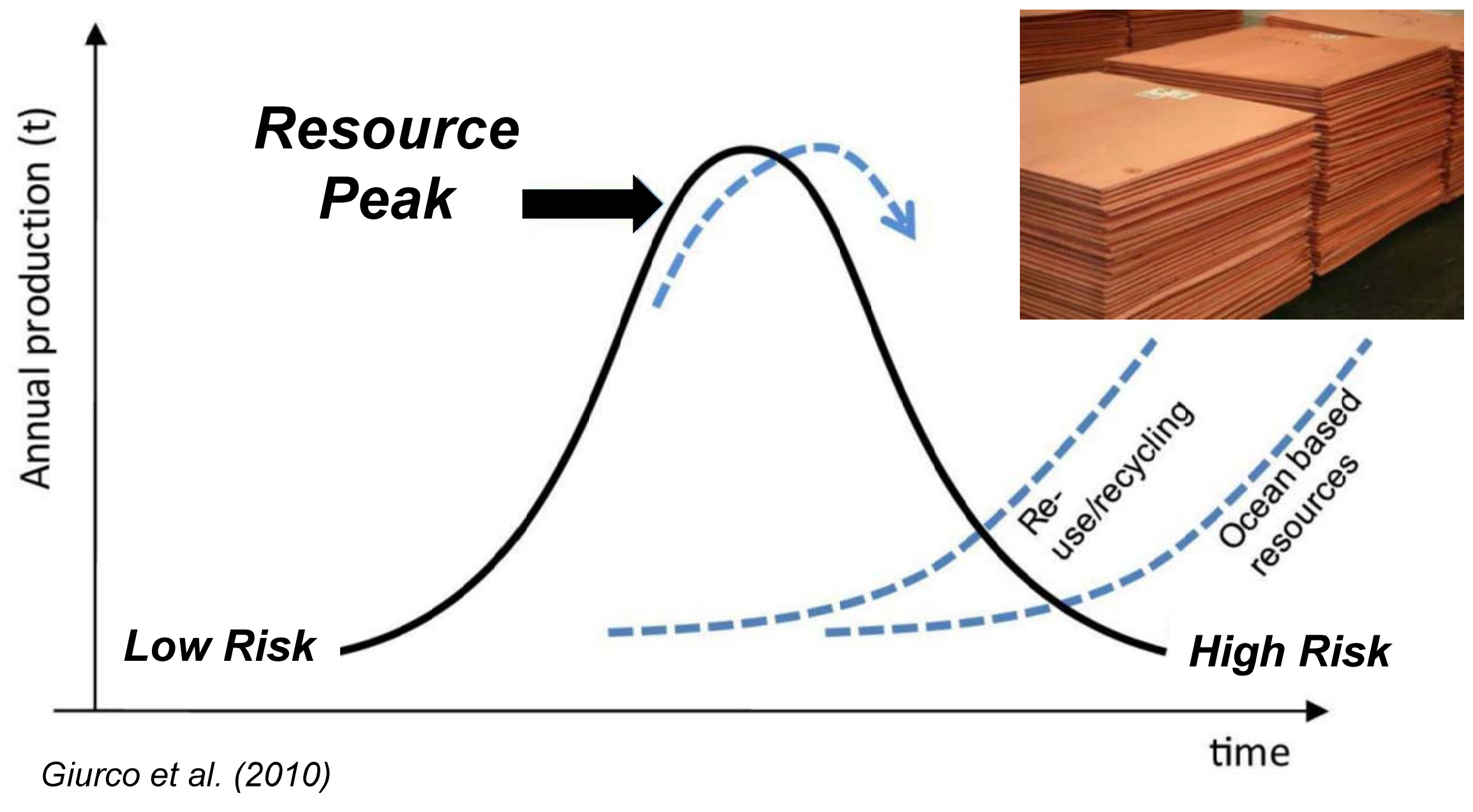



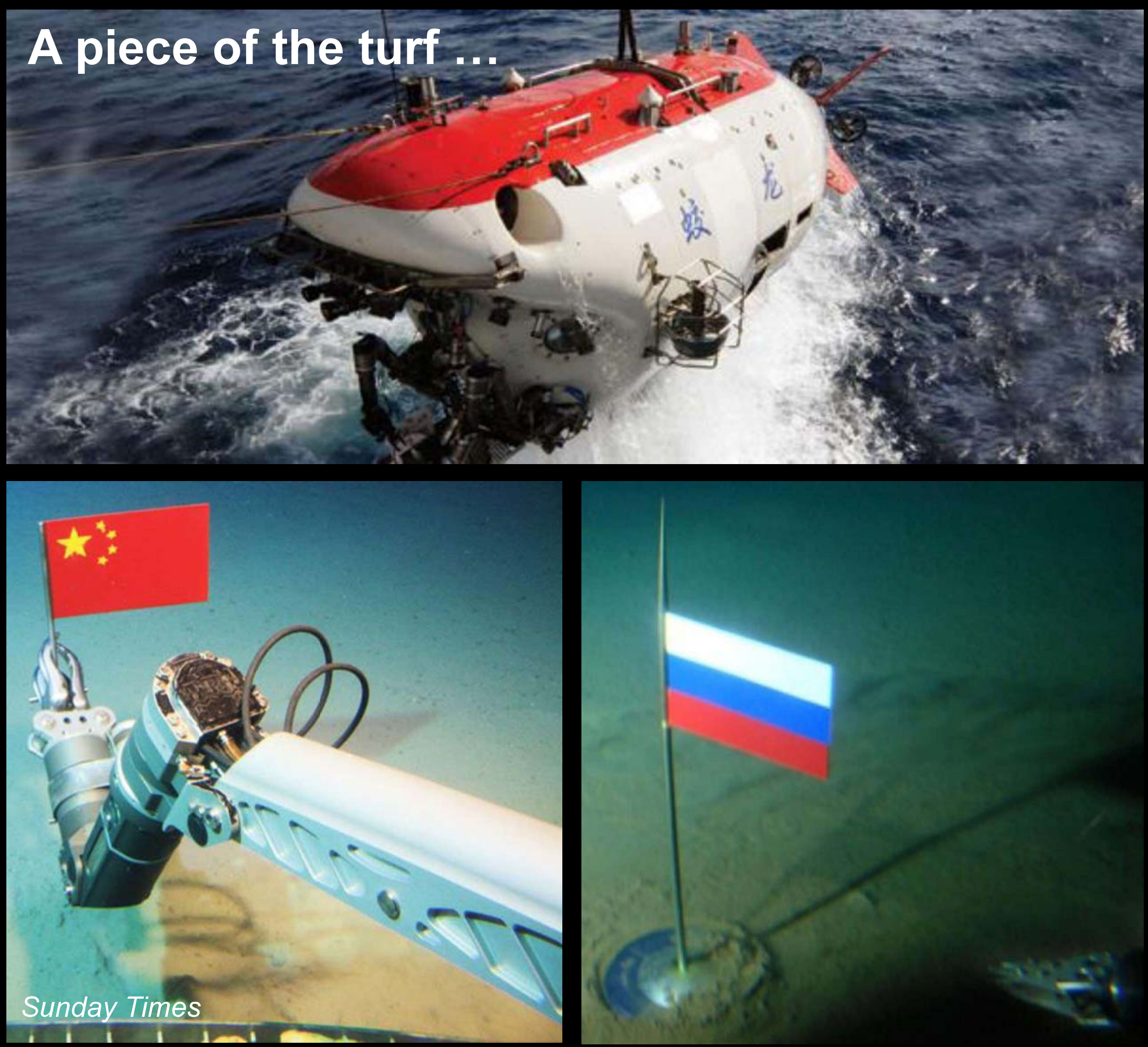


\section{How do we know we are in the right place?}

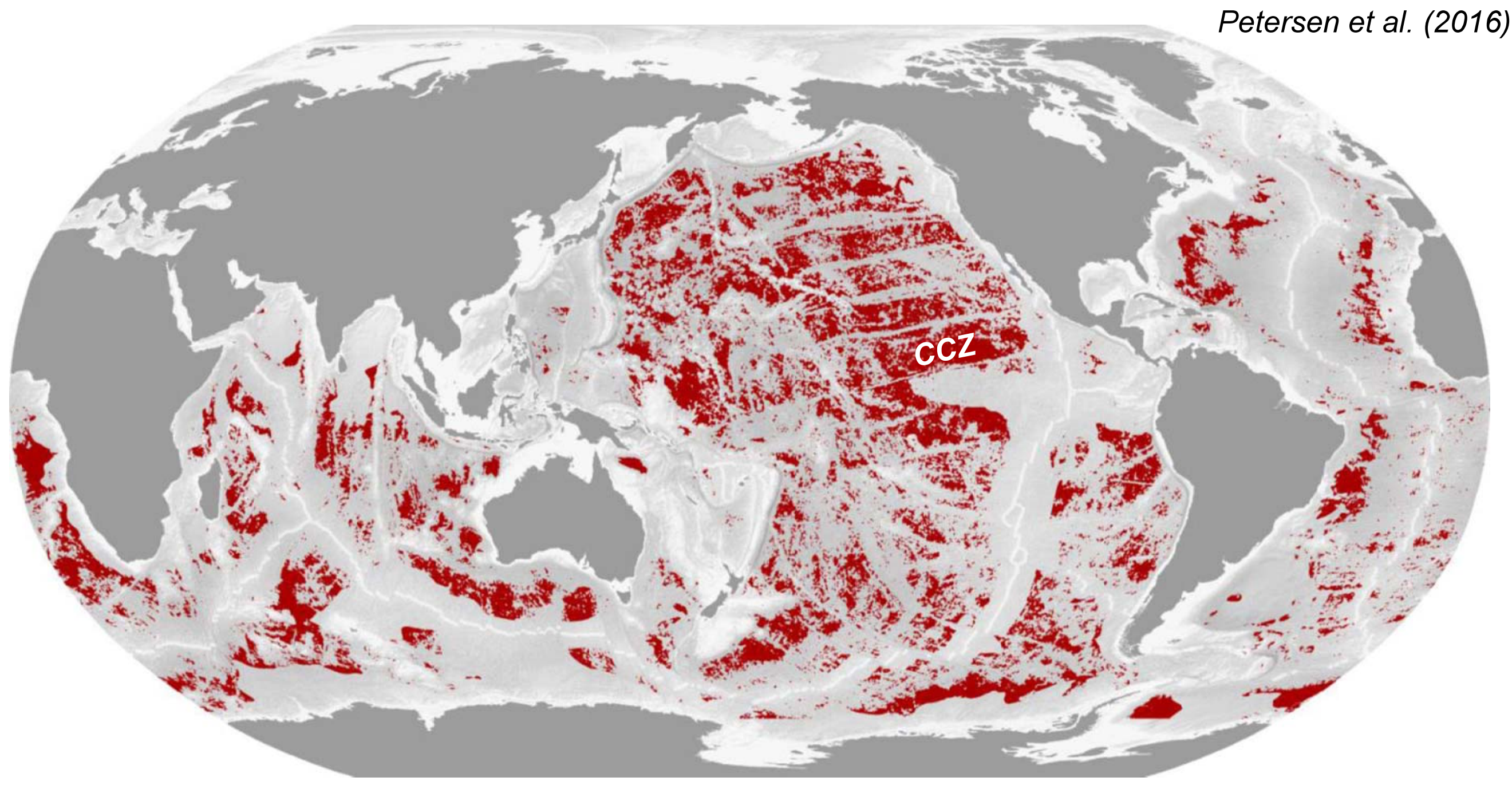

Geological model of nodule distribution 


\section{Mid-Ocean Ridge Sulfides and the Ring of Fire}

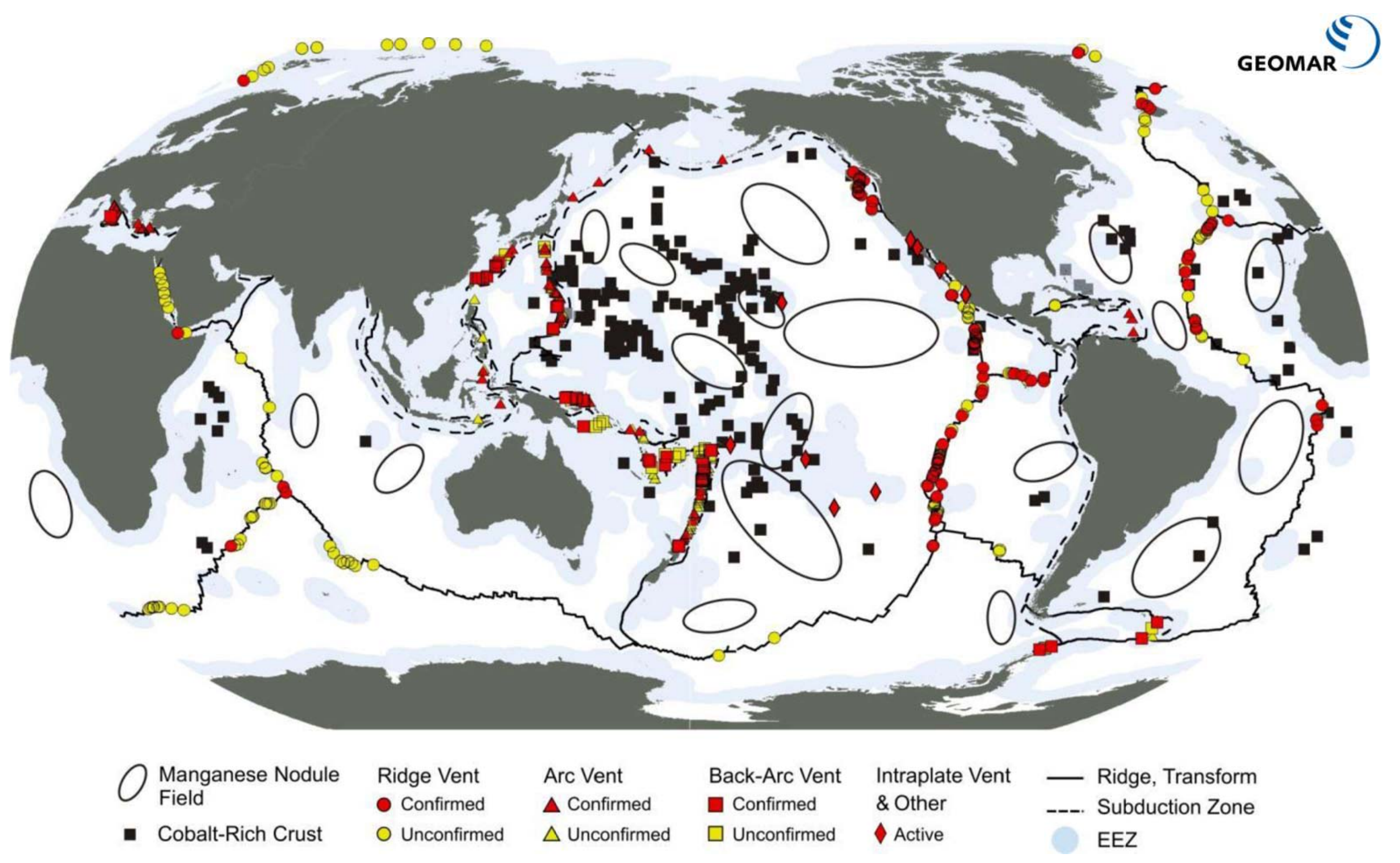




\section{Cumulative tonnage in the neovolcanic zones ...}

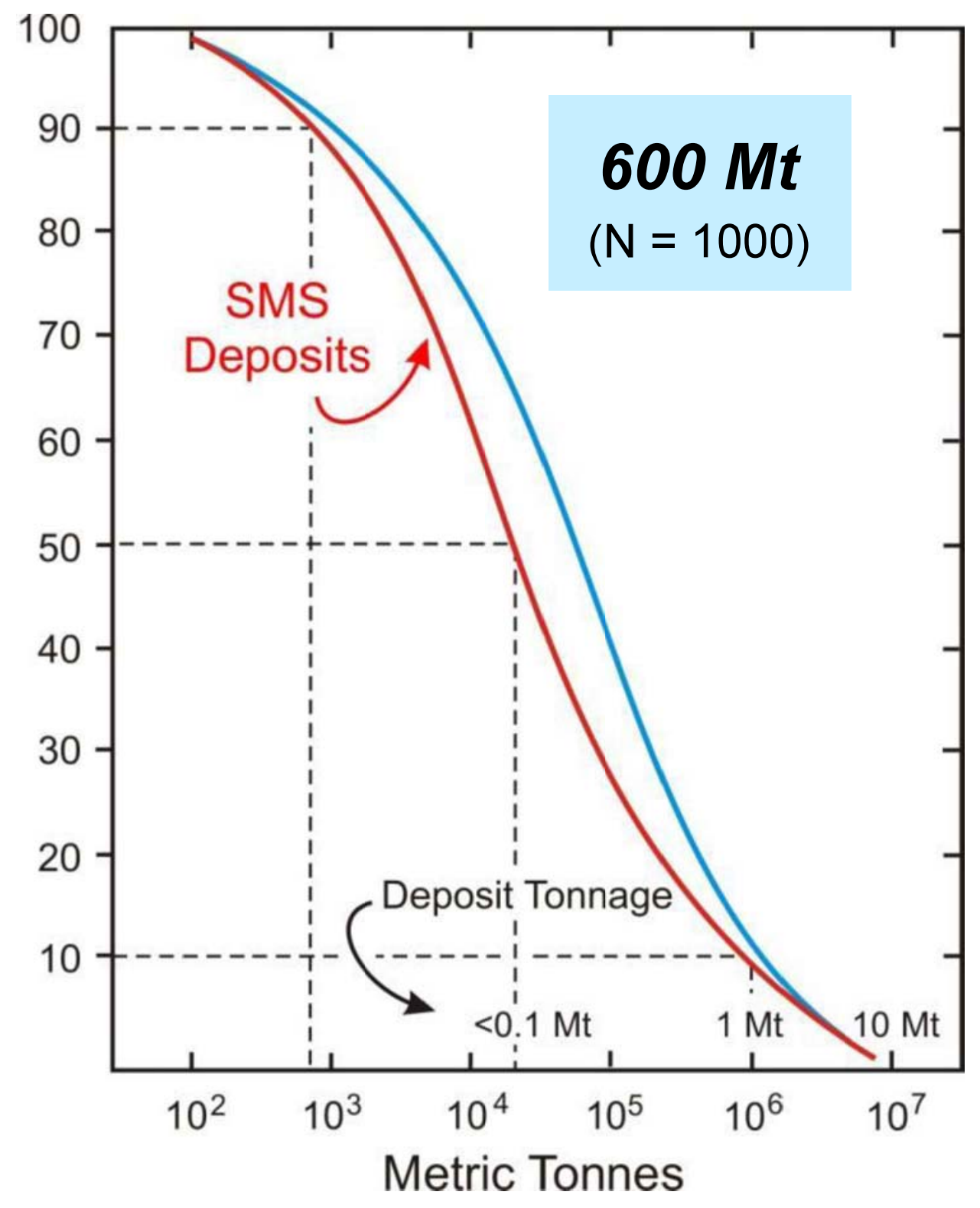




\section{New developments?}

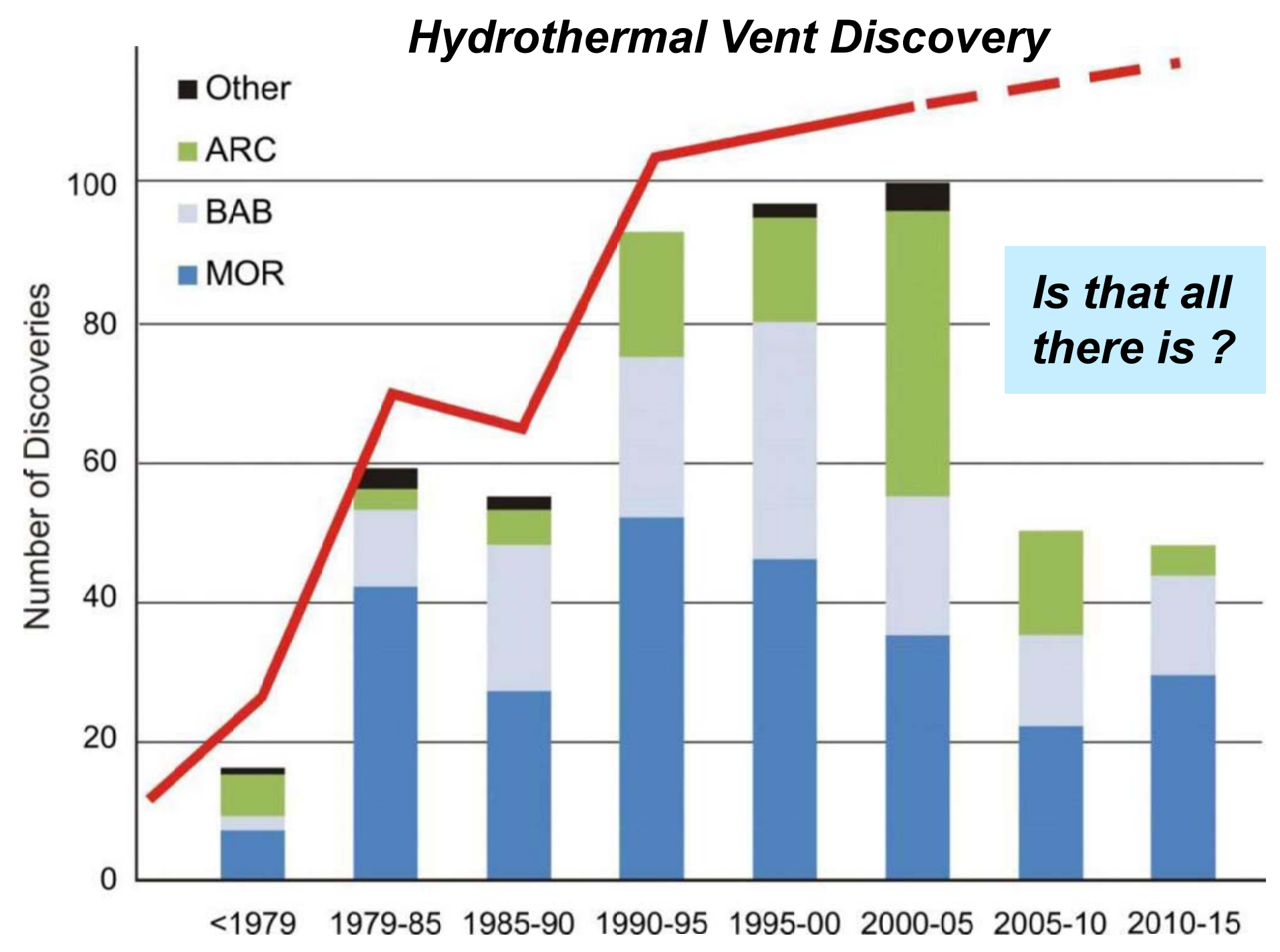





\section{Could we do it?}

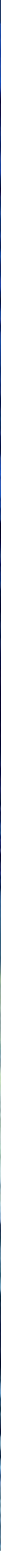




\section{Could we do it?}

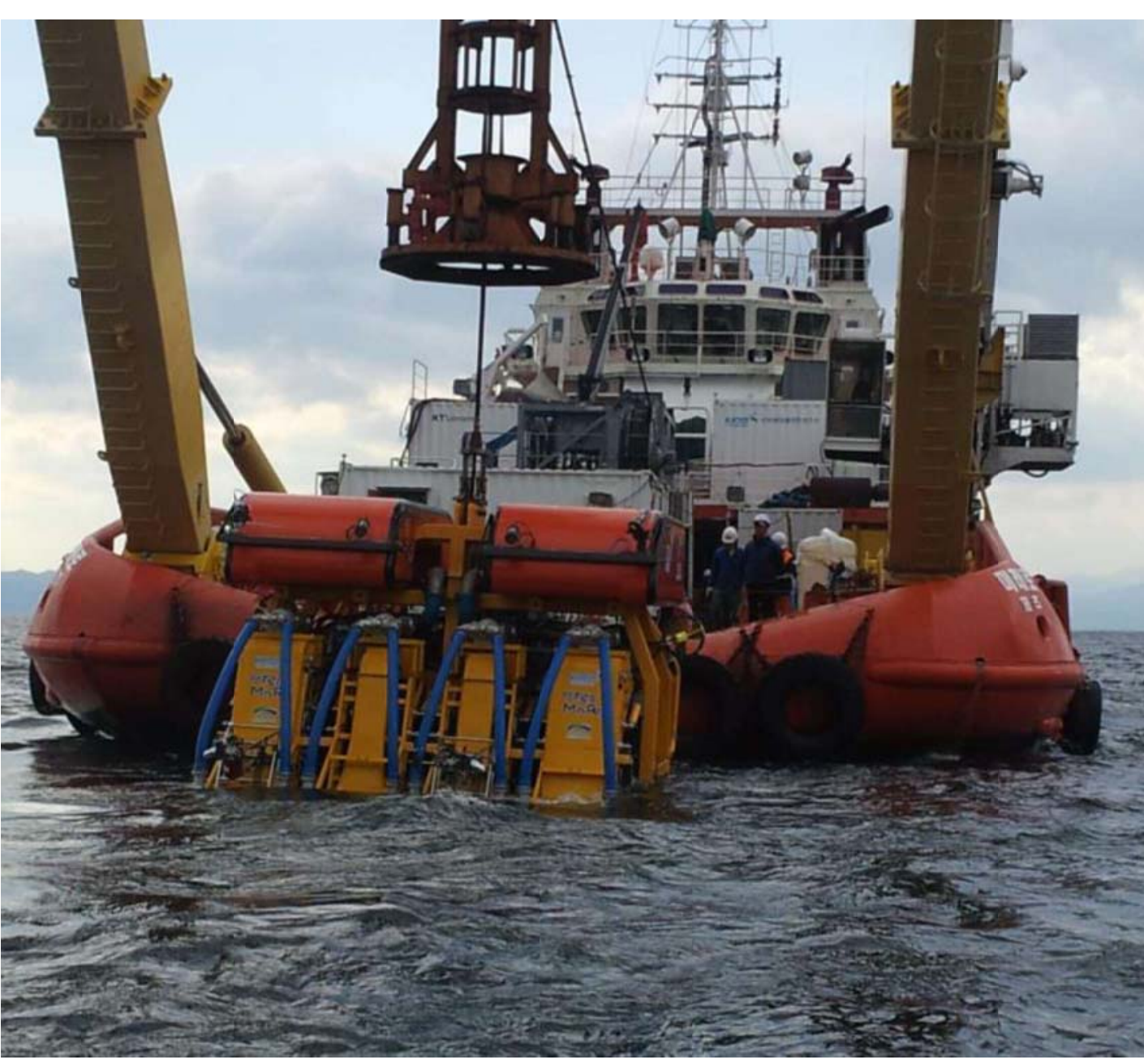

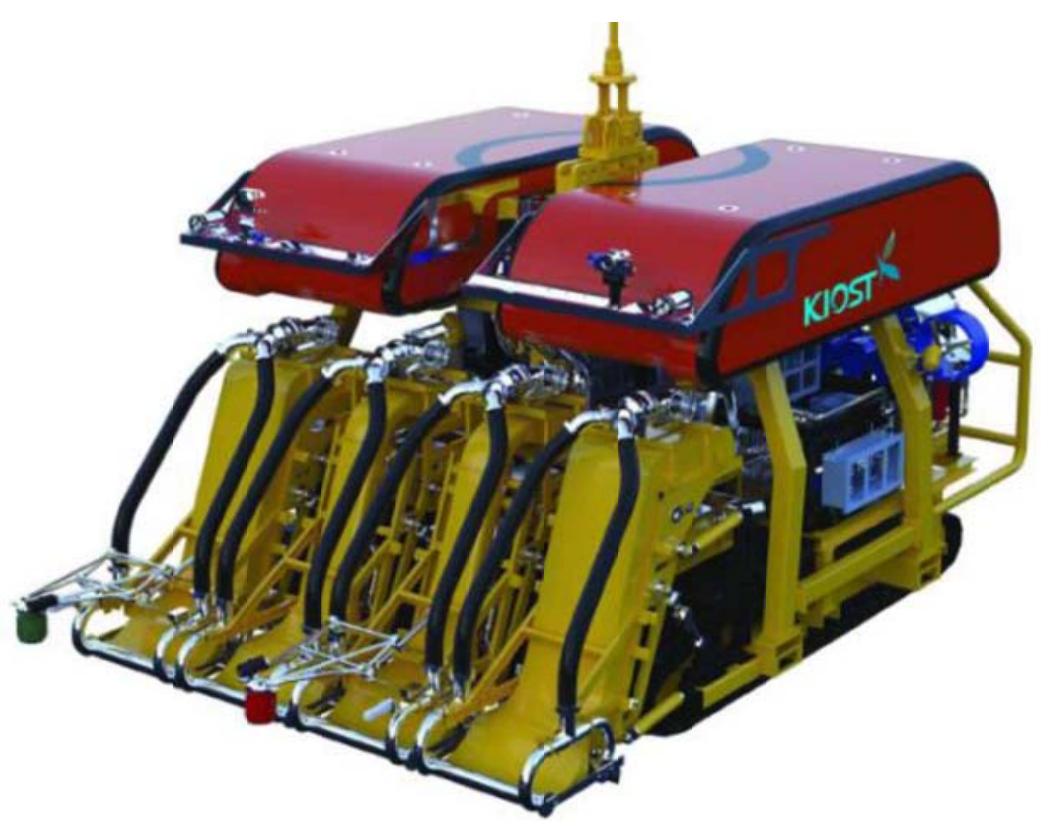

Pilot Mining Robot for Polymetallic Nodules and Pre-Pilot Mining Tests

Sup Hong, Hyung-Woo Kim, Tae-kyeong Yeu, Jong-su Choi, Suk-min Yoon, Jin-ho Kim, Chang-Ho Lee, Cheon-Hong Min, Min-Uk Lee, Ki-Young Sung and Jae-Won $\mathrm{Oh}$

Ocean System Engineering Research Division/Korea Institute of Ocean Science \& Technology (KIOST) 


\section{Could we mine this?}

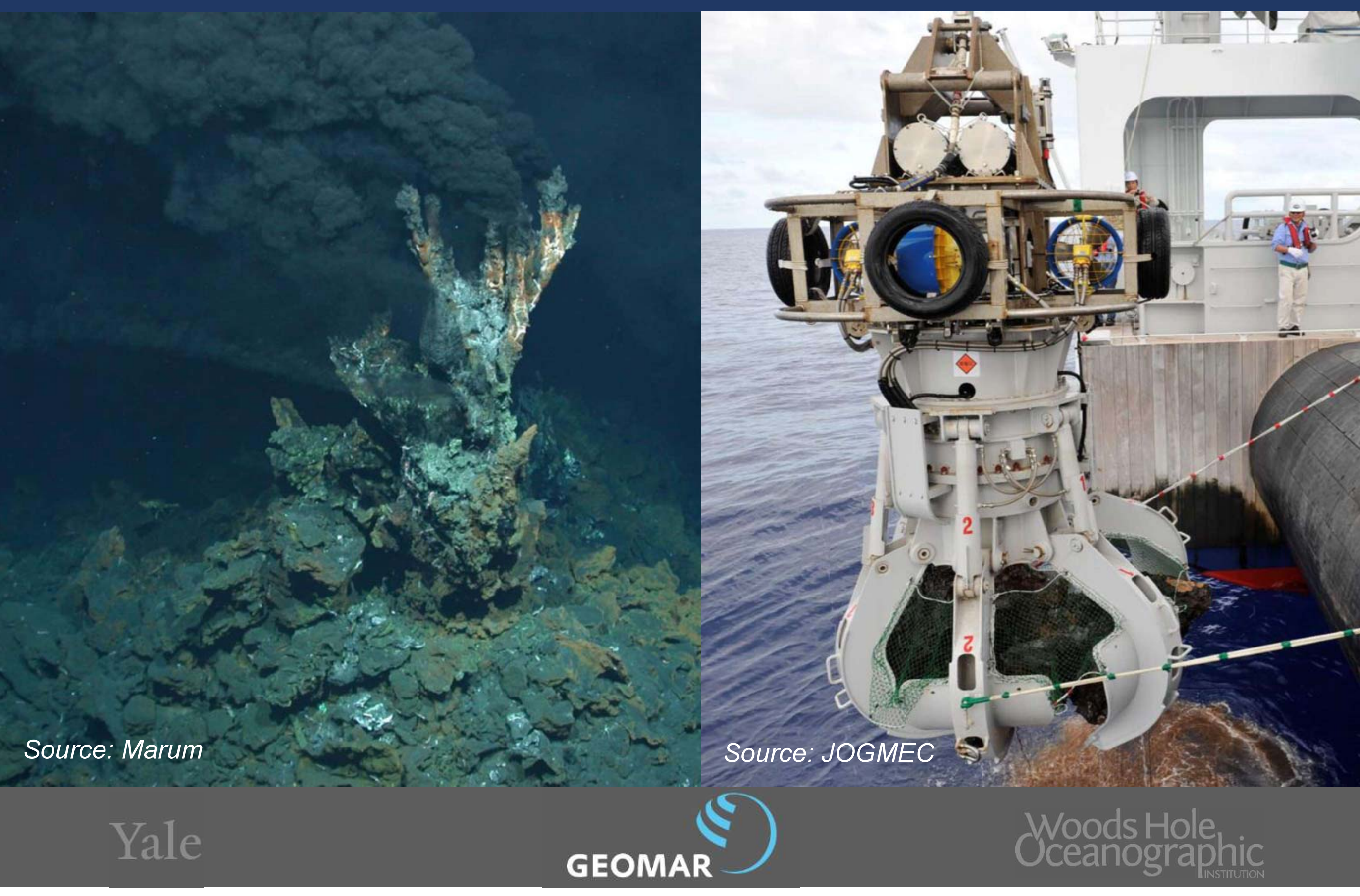




\section{What would deep-sea mining cost?}

\begin{tabular}{|l|c|c|c|c|c|c|c|c|}
\hline \multicolumn{1}{|c|}{$\$ /$ ton } & $\mathrm{Ni}$ & $\mathrm{Co}$ & $\mathrm{Cu}$ & $\mathrm{Zn}$ & $\mathrm{Pb}$ & $\mathrm{Ag}$ & $\mathrm{Au}$ & Value \\
\hline Nodules & $\$ 133$ & $\$ 68$ & $\$ 61$ & & & & & $\$ 262$ \\
\hline Crusts & $\$ 43$ & $\$ 218$ & $\$ 6$ & & & & & $\$ 267$ \\
\hline Sulfides & & & $\$ 277$ & $\$ 261$ & $\$ 21$ & $\$ 53$ & $\$ 76$ & $\$ 635$ \\
\hline
\end{tabular}

\section{The fine print ... a great deal of uncertainty}

${ }^{1}$ approximate value per tonne based on in situ metal content and January 2017 LME metal prices

2assuming $1.3 \% \mathrm{Ni}, 1.1 \% \mathrm{Cu}, 0.2 \% \mathrm{Co}$ in nodules and $0.4 \% \mathrm{Ni}, 0.1 \% \mathrm{Cu}$, and $0.7 \% \mathrm{Co}$ in crusts, excluding Mn (up to $\$ 400 /$ tonne) which is available in high-grade land deposits

3 assuming ore containing $5 \% \mathrm{Cu}, 10 \% \mathrm{Zn}, 1 \% \mathrm{~Pb}, 100 \mathrm{~g} \mathrm{Ag}$, and $2 \mathrm{~g} \mathrm{Au} \mathrm{per} \mathrm{tonne}$

4base metal prices/tonne: \$1740 (Mn), \$10240 (Ni), \$32500 (Co), \$5500 (Cu), \$2600 (Zn), \$2060 (Pb)

\section{Yale}


Bingham Canyon Copper Mine, Utah

- Land use, land access

- Acid drainage, rock waste

\section{- Energy, emissions}

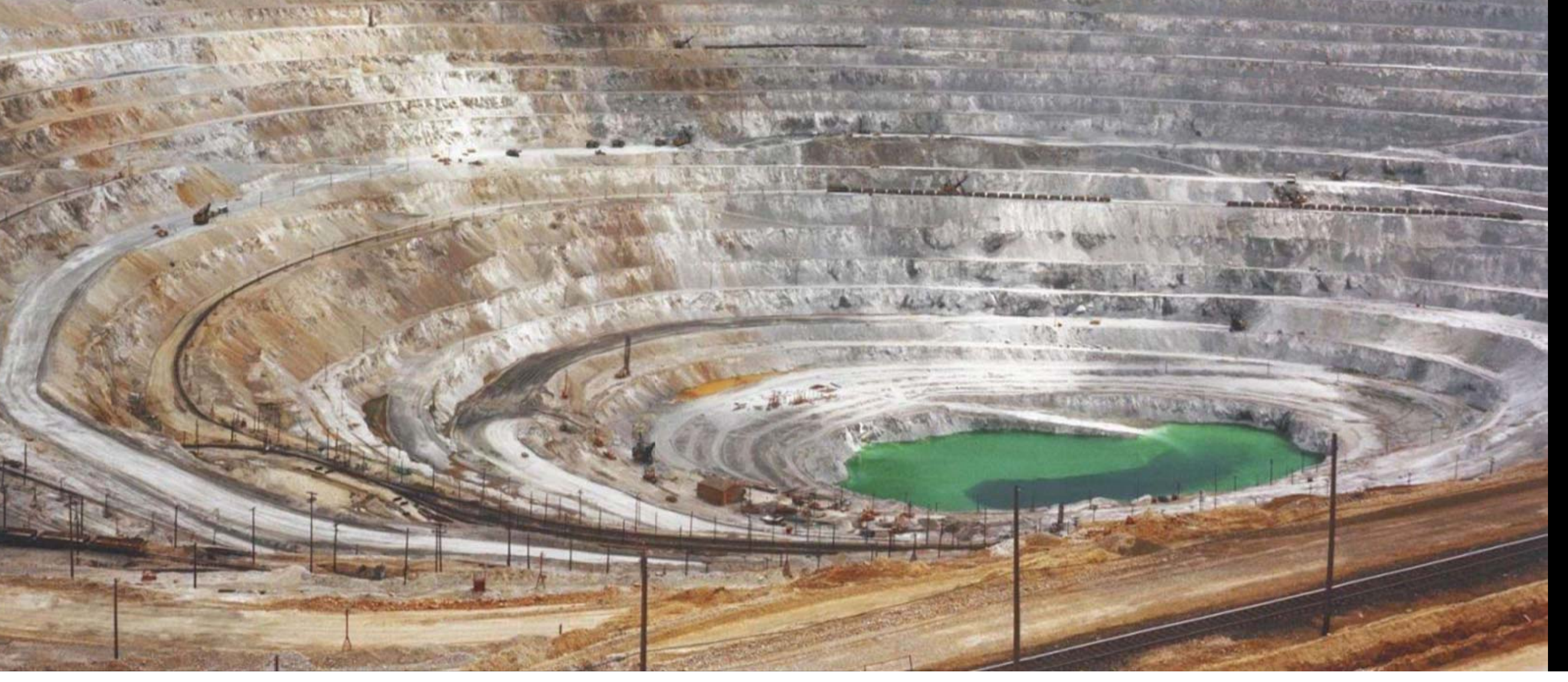




\section{Exploration Licenses: $1,898,350$ km$^{2}$}

- Active licenses in the Area: $1,055,000 \mathrm{~km}^{2}$

- Commercial licenses in EEZs: $843,350 \mathrm{~km}^{2}$

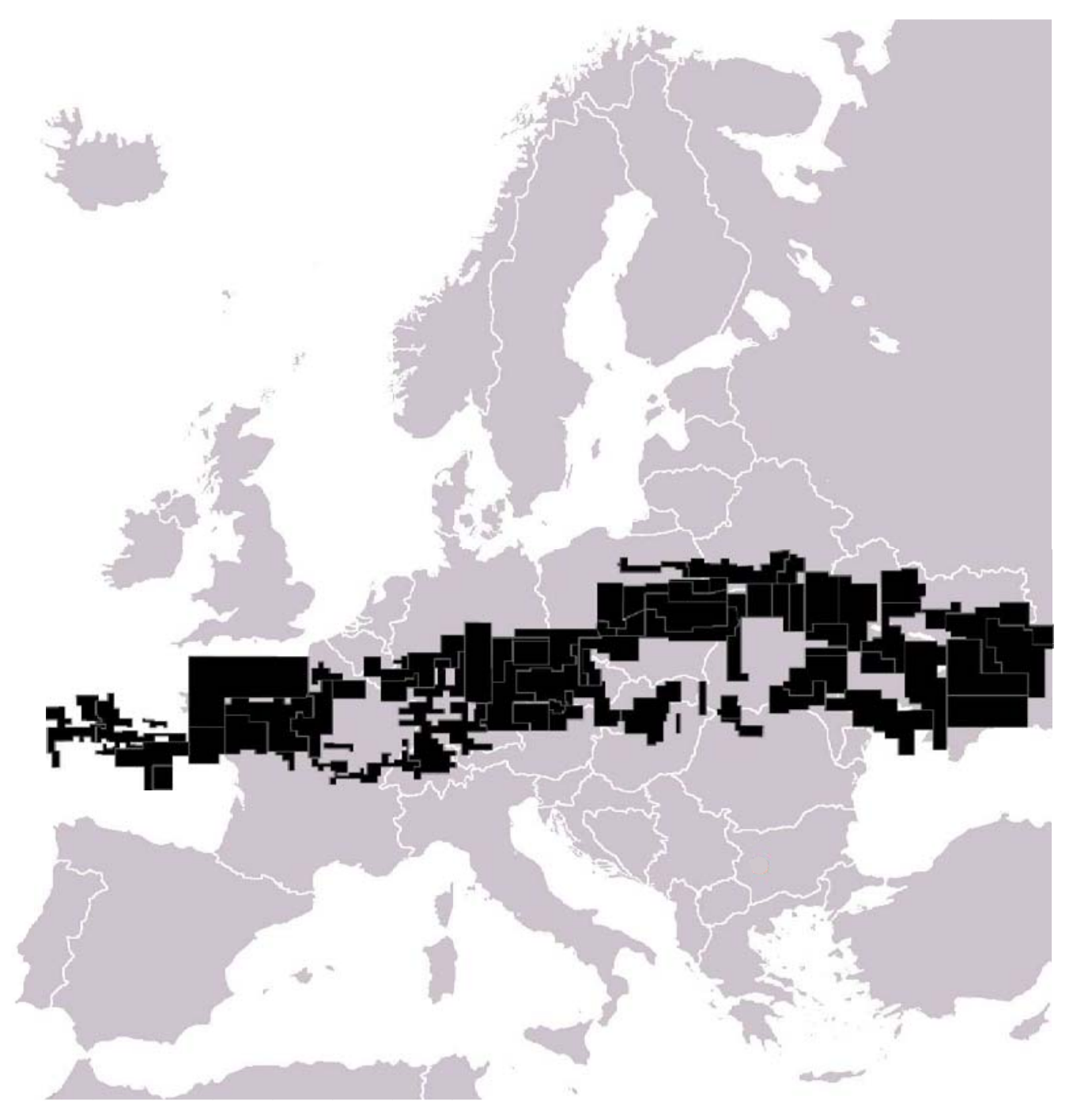




\section{Some bottom lines for deep-sea mining?}

\section{Nodules}

- lots of them, they will be mined, there will be impacts

- it's possible that nobody will make any money

- that might not matter in some cases

\section{Sulfides}

- current inventory not enough to make a difference

- some companies could make money on high-grade deposits

- large deposits have not been found that could compete with land-based mines

\section{Crusts}

- technical challenges of mining have not been solved

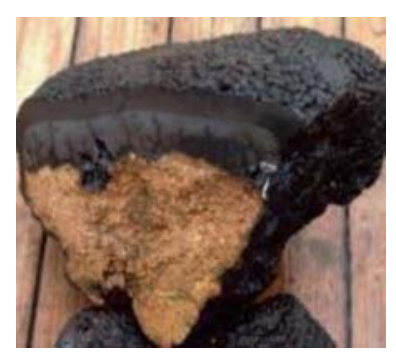




\section{A way forward for science?}

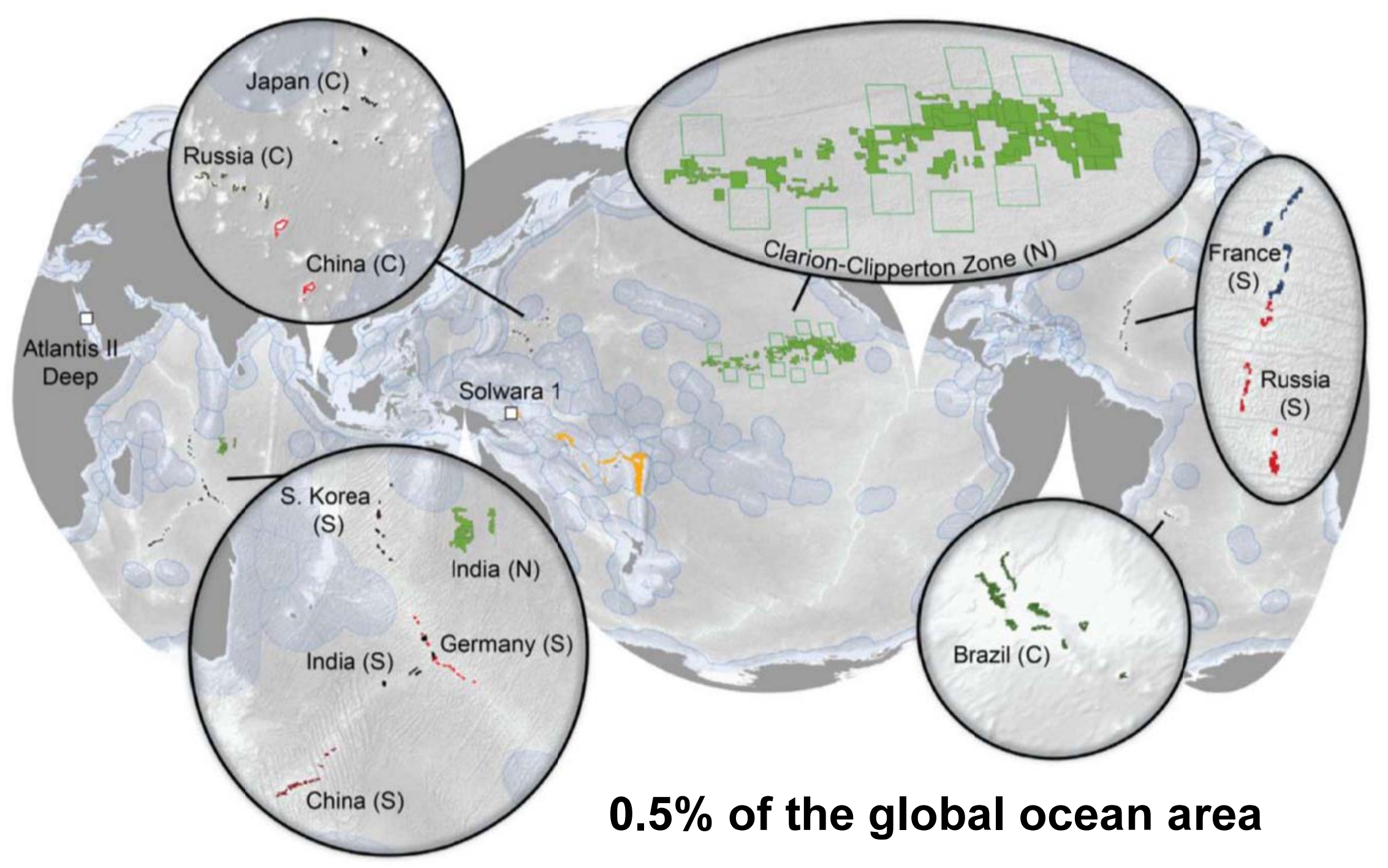

Petersen et al. (2016) 


\section{A way forward for science ...}

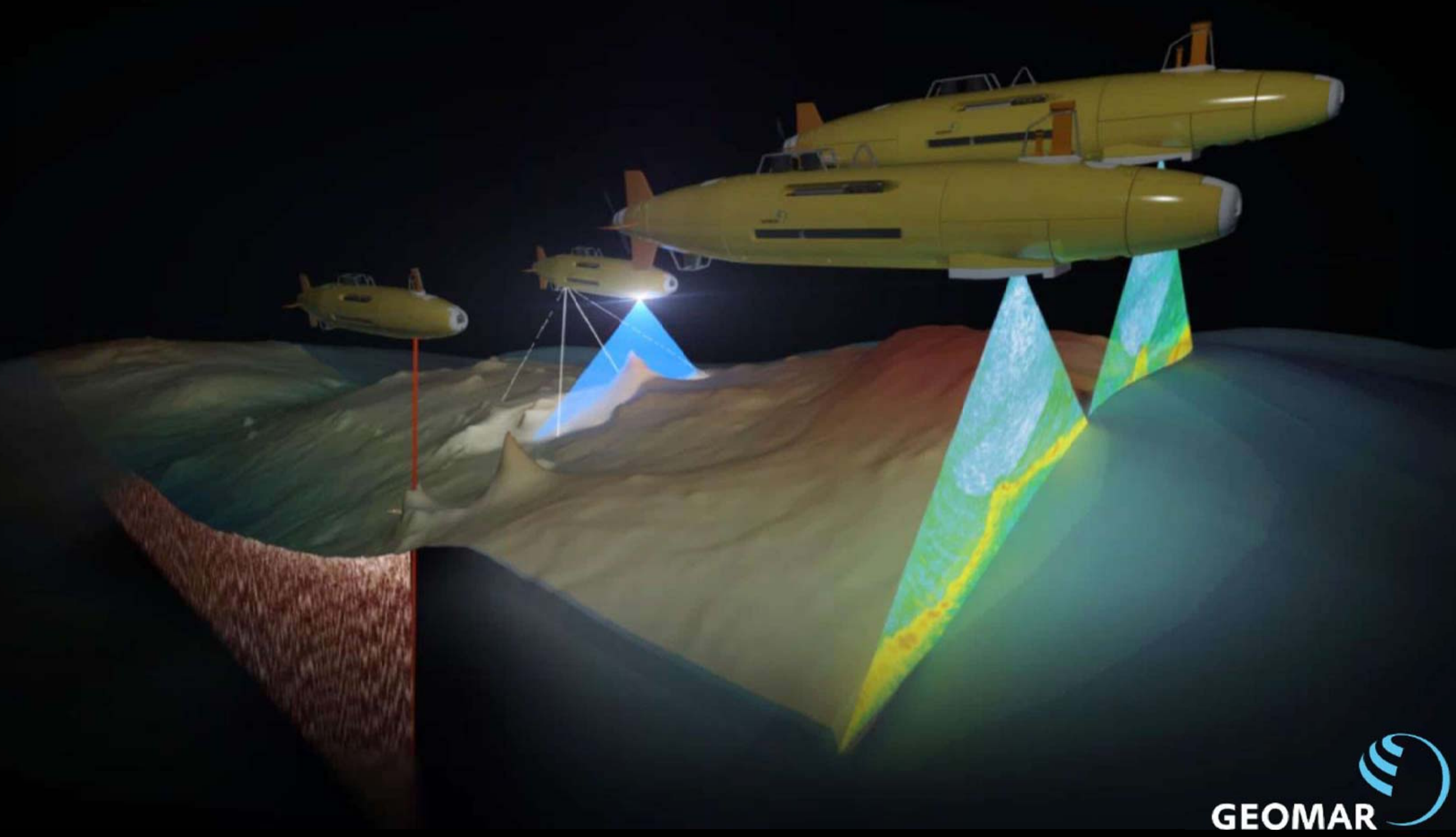

Keep Exploring ... 


\title{
Ecosystem Services from the Deep Sea
}

\author{
Stace Beaulieu
}

Woods Hole Oceanographic Institution

stace@whoi.edu

\section{Should We Mine the Seafloor?}

AAAS 2017 Annual Meeting, February 18, 2017 


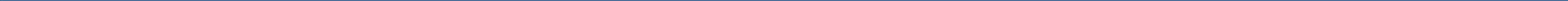




\section{Should We Mine the Seafloor?}

\section{First question for deep-sea biologists:}

What environmental impacts do you anticipate from deep-sea mining?

NEW question for natural and social scientists, working together:

What ECONOMIC impacts do you anticipate from lost or degraded ecosystem services? 


\section{Ecosystem services:}

Broadly defined as services that contribute to human well-being

Provisioning
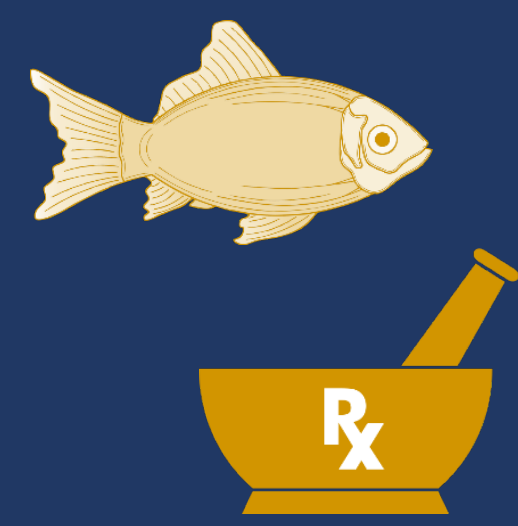

Regulating

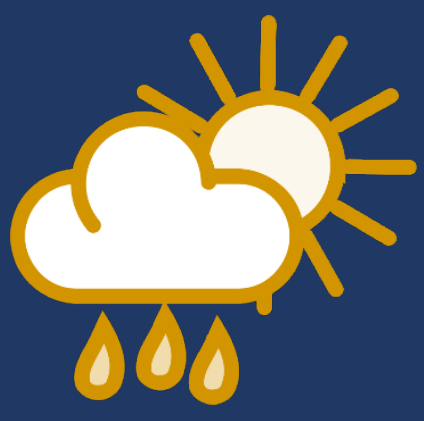

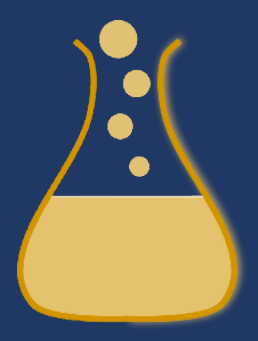

Cultural

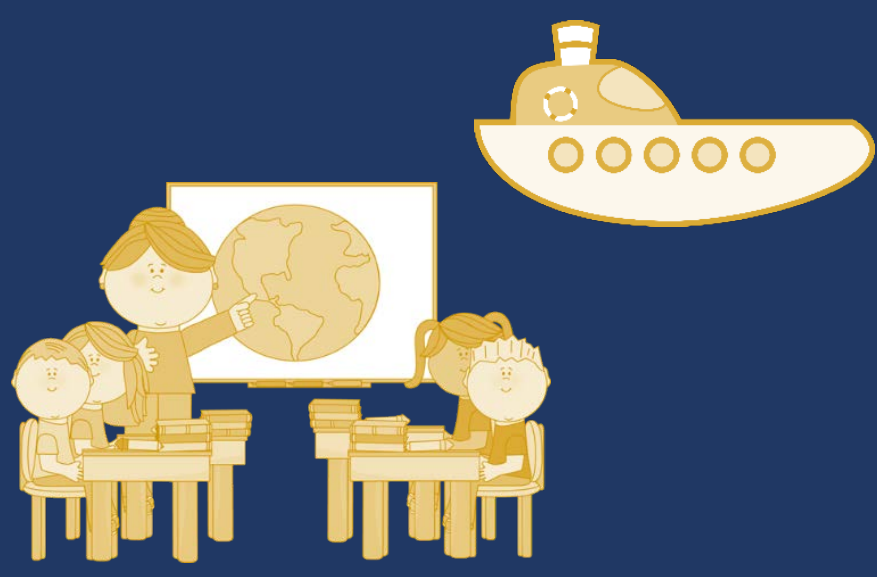

And the biodiversity and services that support those above, such as dispersal and connectivity 
What are the deep-sea ecosystems that may be subject to deep-sea mining?

Food-limited ecosystems

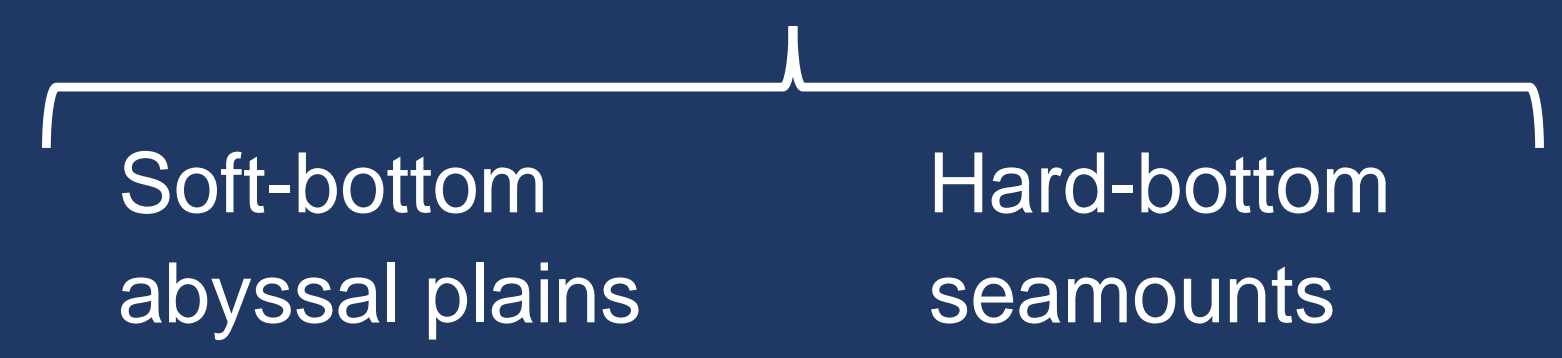

Chemosynthesisbased ecosystems

Hydrothermal vents 


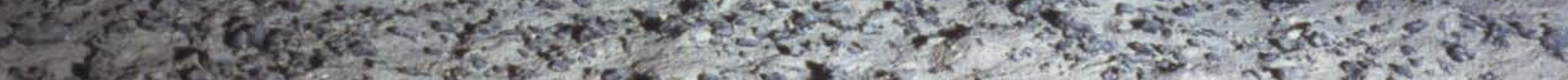

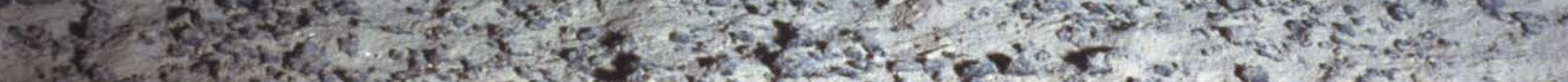

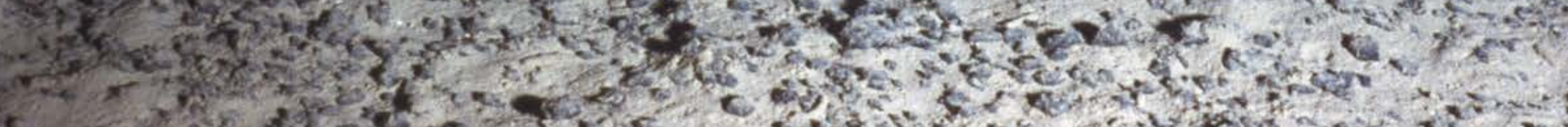

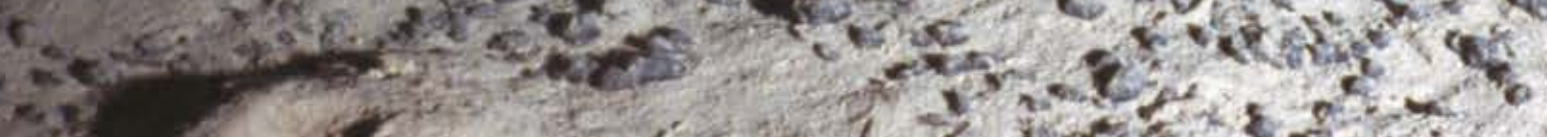

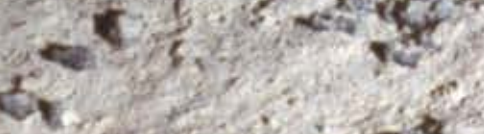

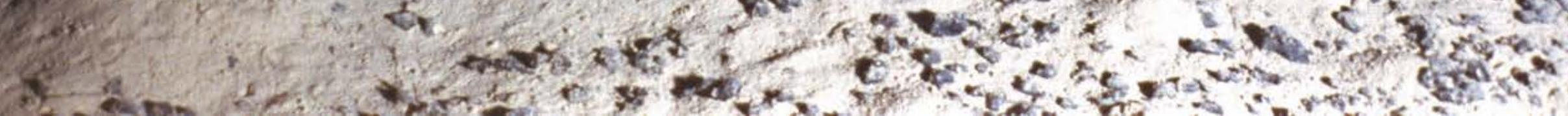 2.

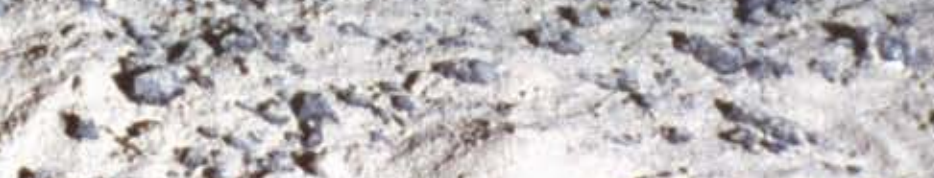

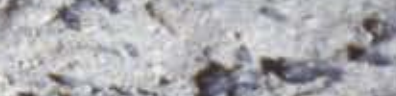

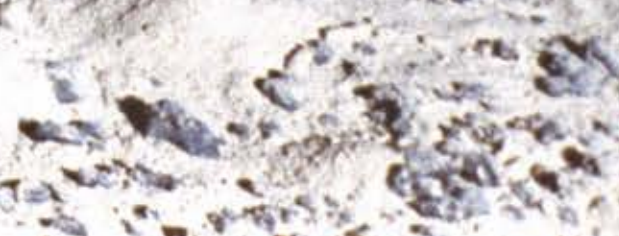

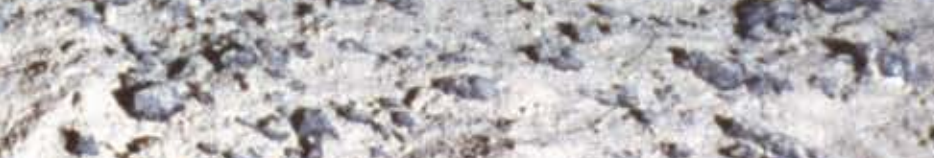

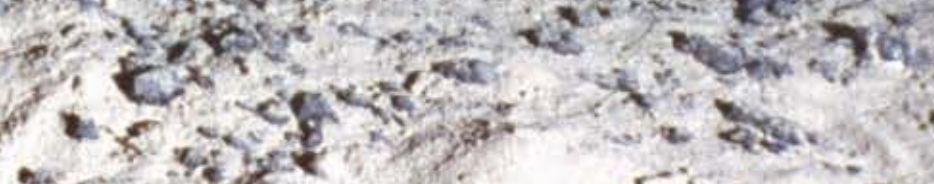 - 


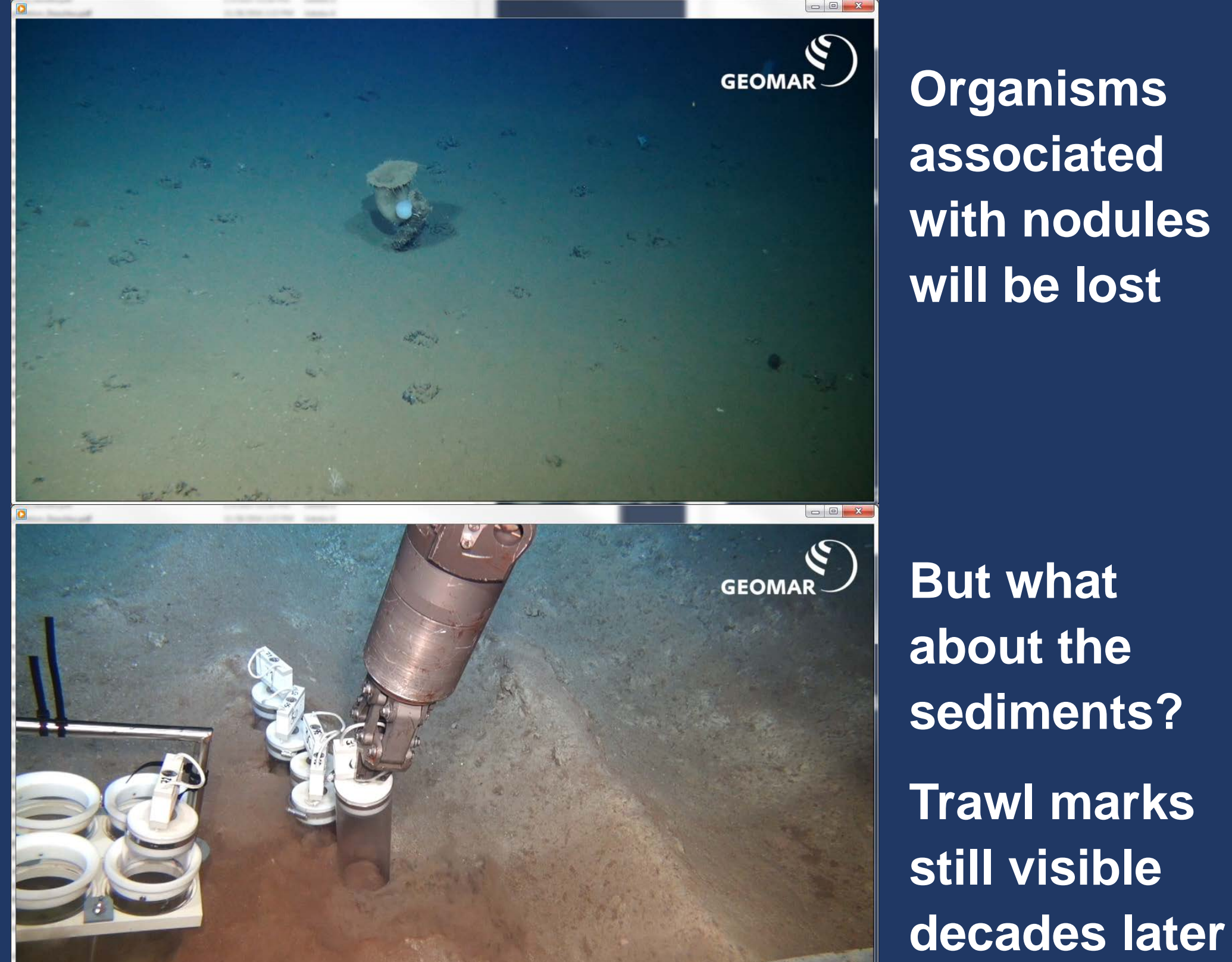




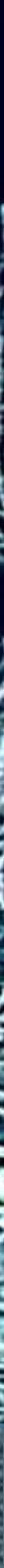






\section{Bamboo corals can live for a century, or more}




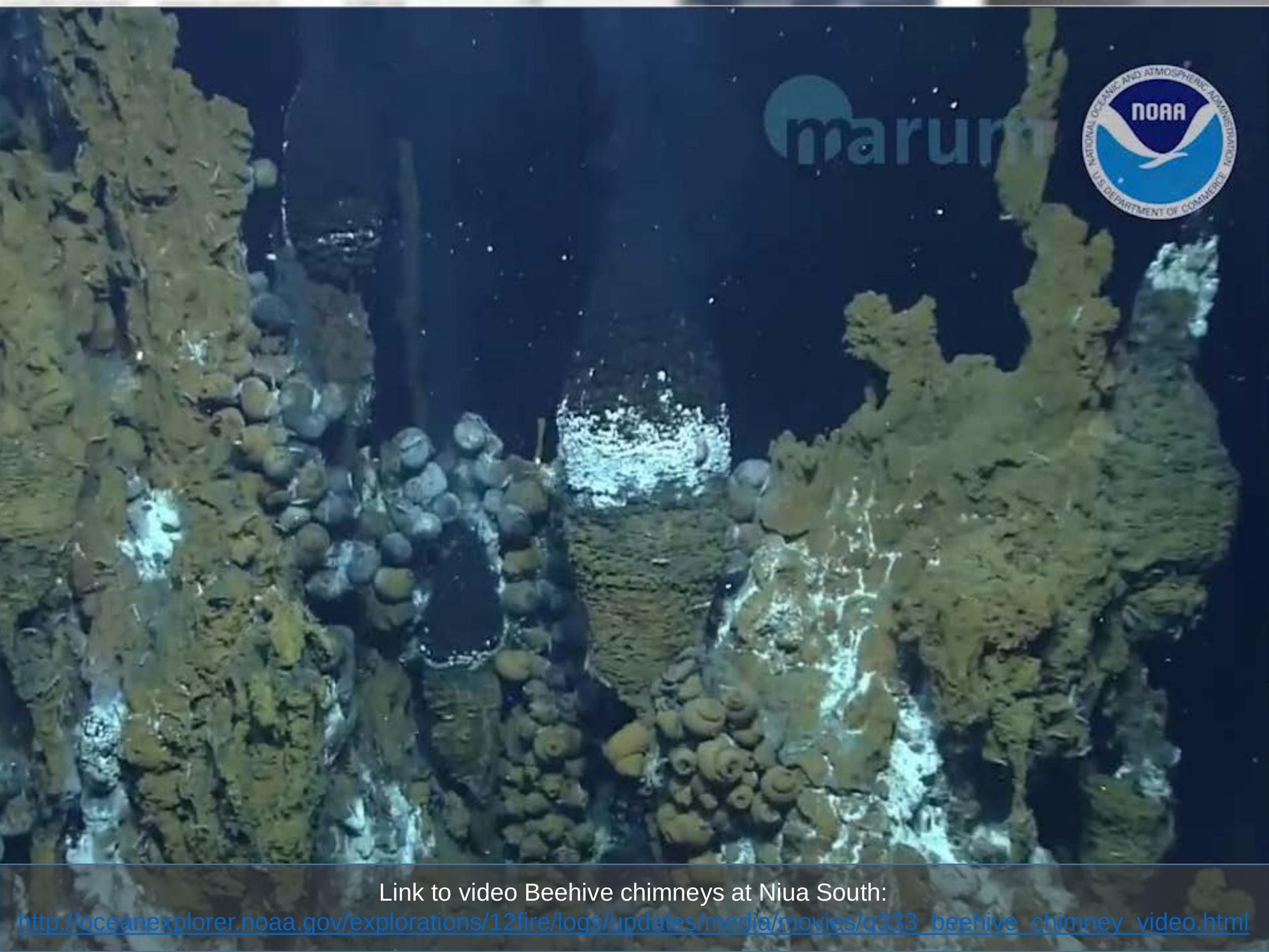




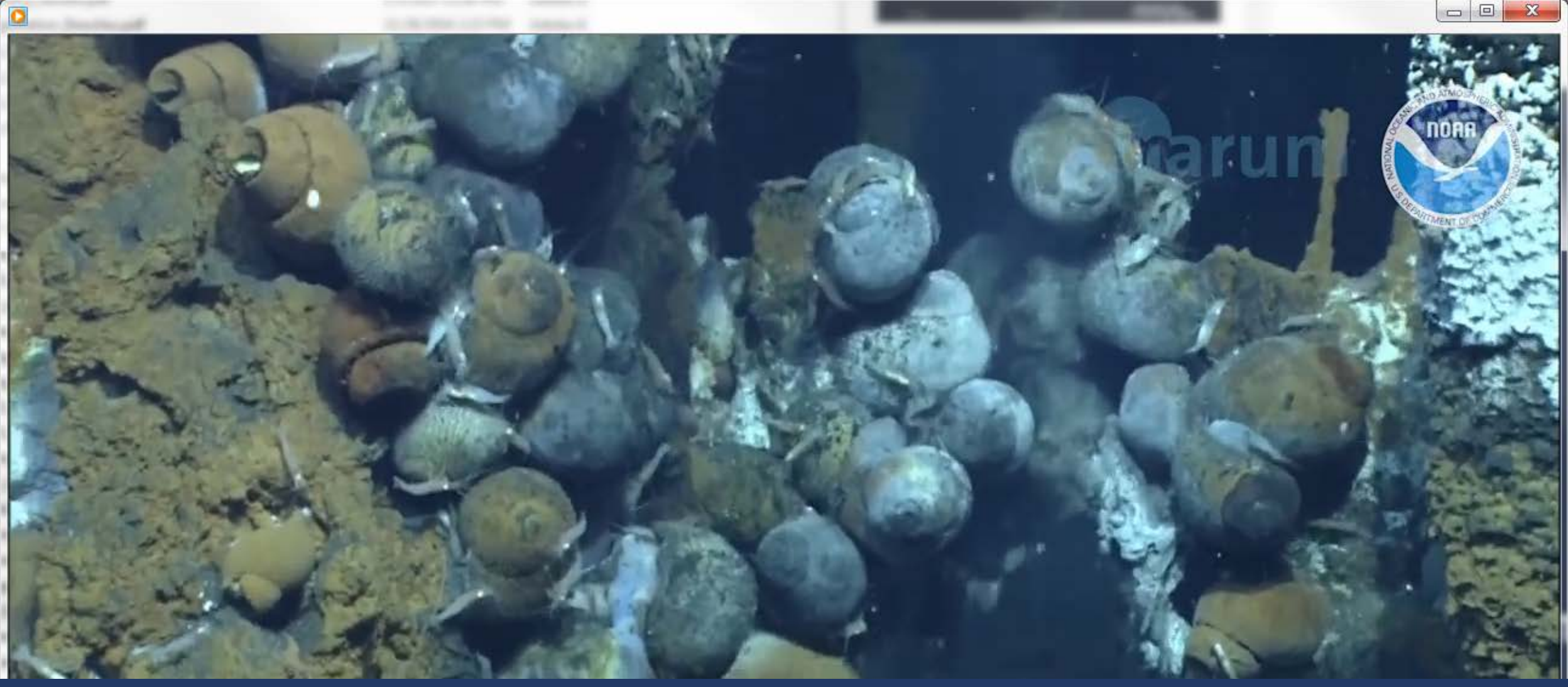

\section{Hydrothermal vent ecosystems may be subject to catastrophic natural disturbances such as volcanic eruptions *}

\footnotetext{
* Note added after the presentation: Only a handful of vent sites on Earth have been observed after a volcanic eruption. Observational and modeling studies are needed to understand the vulnerability and resilience of vent ecosystems in a broad range of tectonic and geological settings.
} 


\section{What environmental impacts do you anticipate from deep-sea mining?}

\section{Answer:}

- Direct effects: loss of habitat and associated organisms

- Indirect effects: sediment plumes

Environmental impacts in many of the targeted habitats are likely to be long-lasting-longer than our lifetimes.

Note: new research in 2016 - international "Ecological Risk Assessment Survey for Deep-Sea Mining in the ABNJ" 


\section{What new research do we need to address this first question?}

Research related to the vulnerability and resilience * of deep-sea ecosystems

Biology + Ecology + Oceanography

* Supporting services: dispersal and connectivity

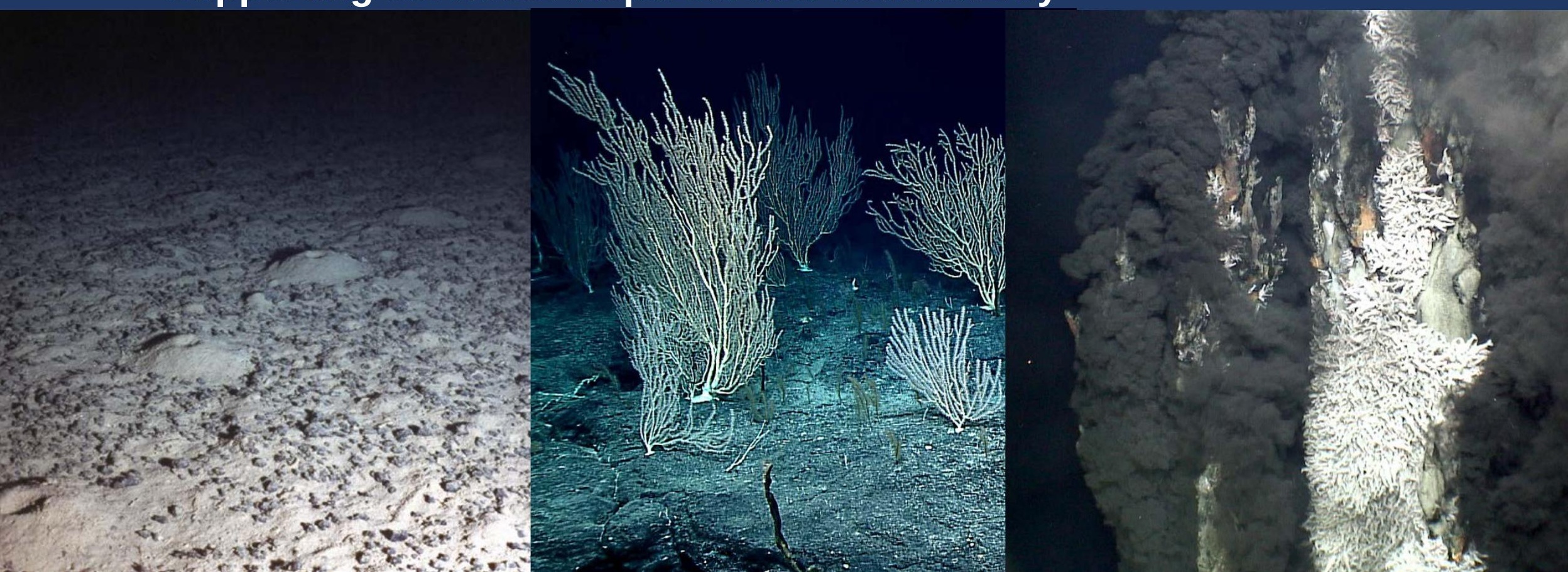




\section{AAAS 2017 Theme: Serving Society Through Science Policy}

How could this science inform policy?

For the seabed beyond the limits of national jurisdiction: regulations for exploitation including environmental regulations are being developed by the International Seabed Authority (ISA)

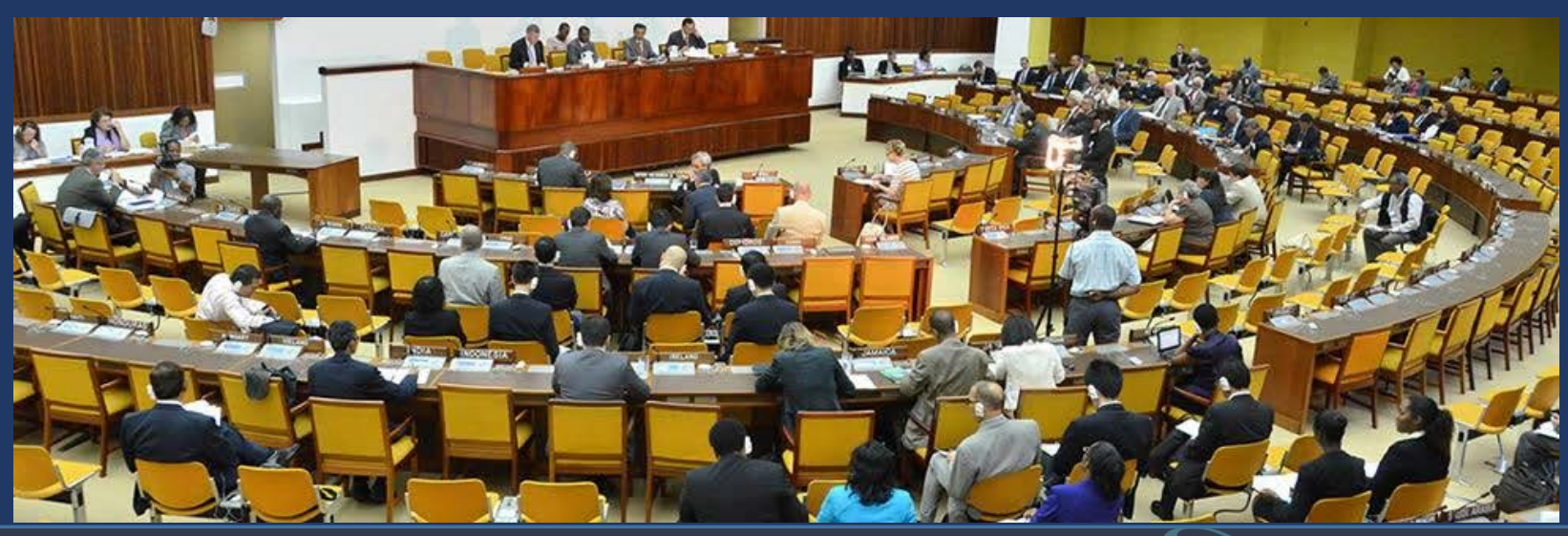




\section{NEW question:}

What ECONOMIC impacts do you anticipate from lost or degraded ecosystem services?

Provisioning
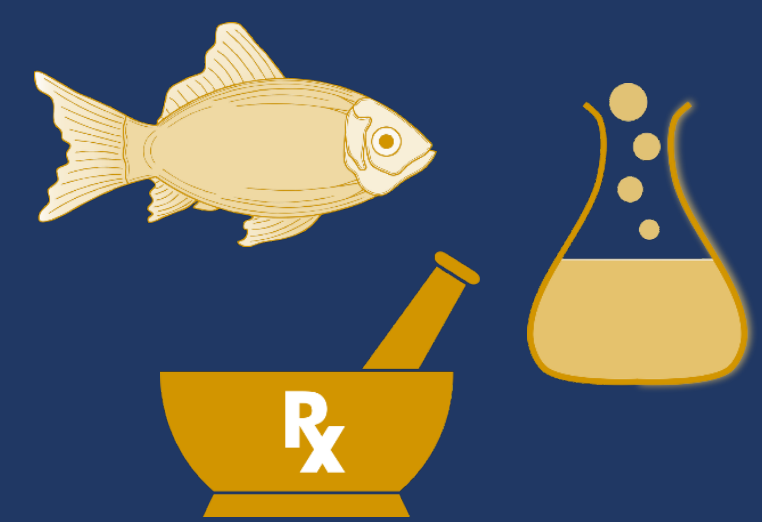

Regulating

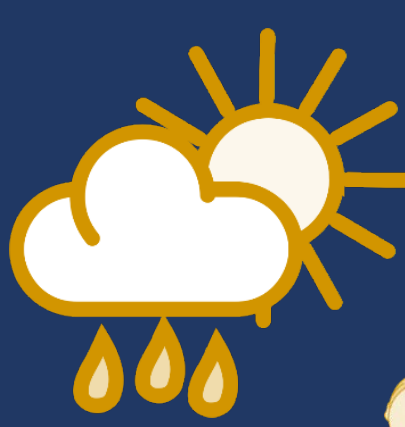

Cultural
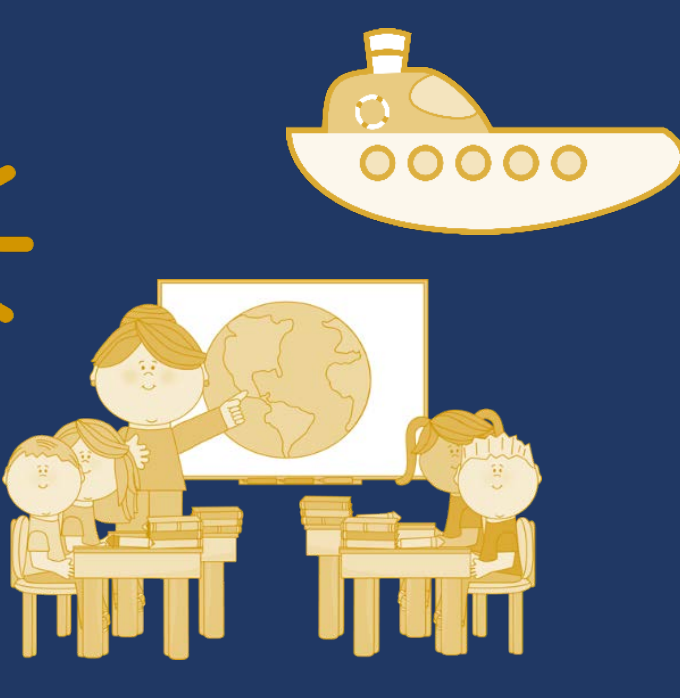

How do we determine values of these services?

And the biodiversity and services that support those above 


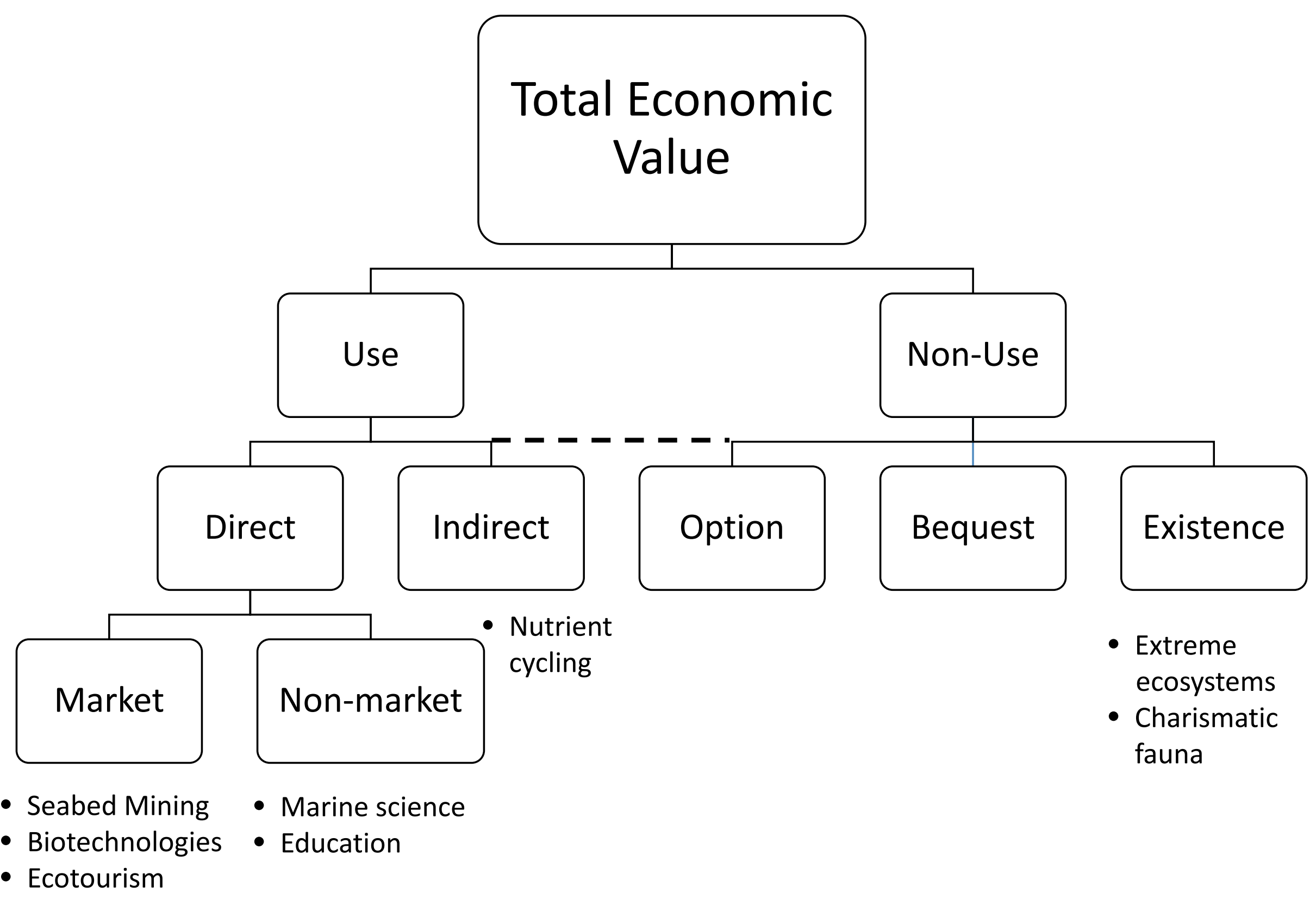




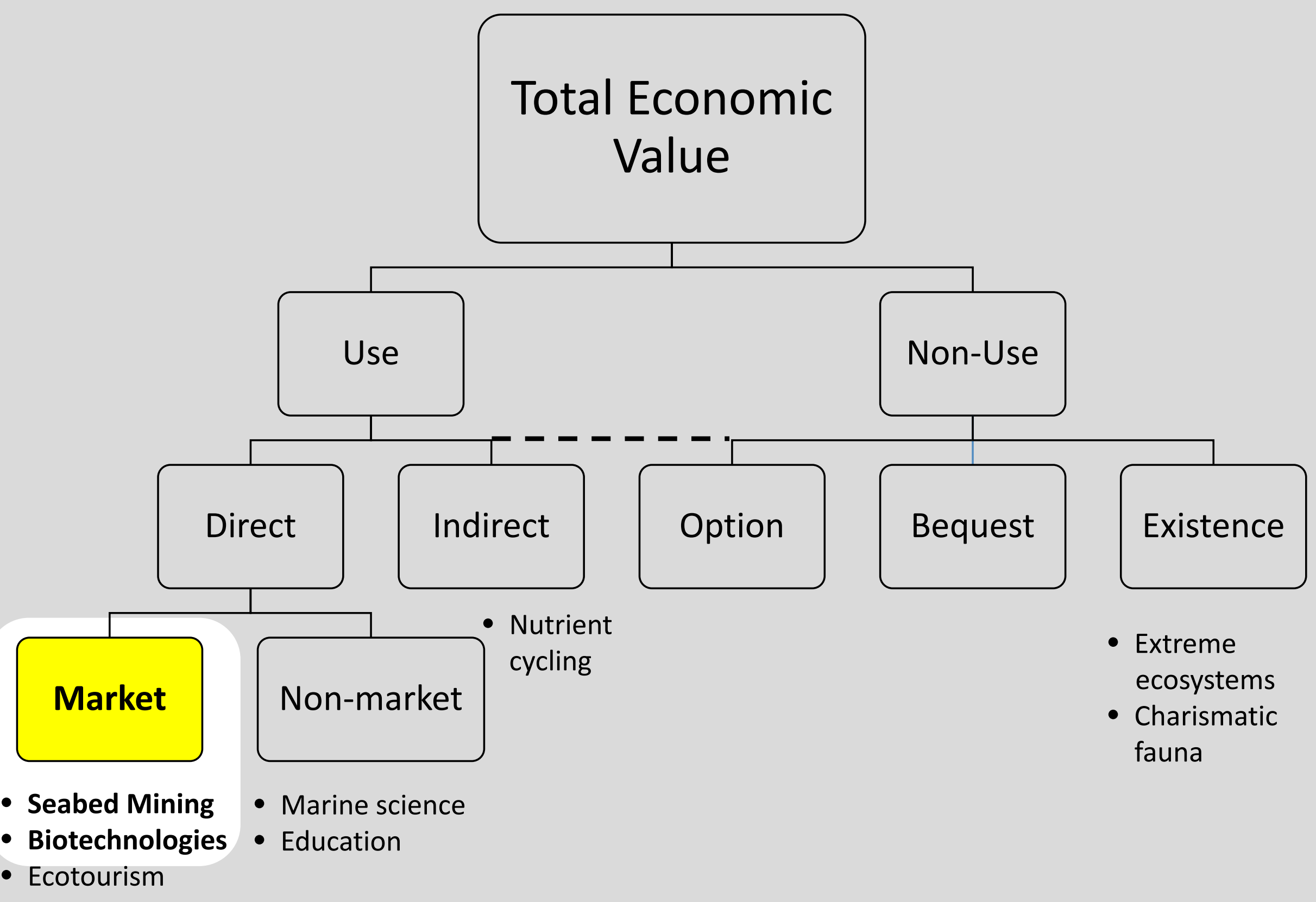


Potential trade-offs in use values: mineral vs. biological resources

\section{Example for provisioning services: pharmaceuticals}

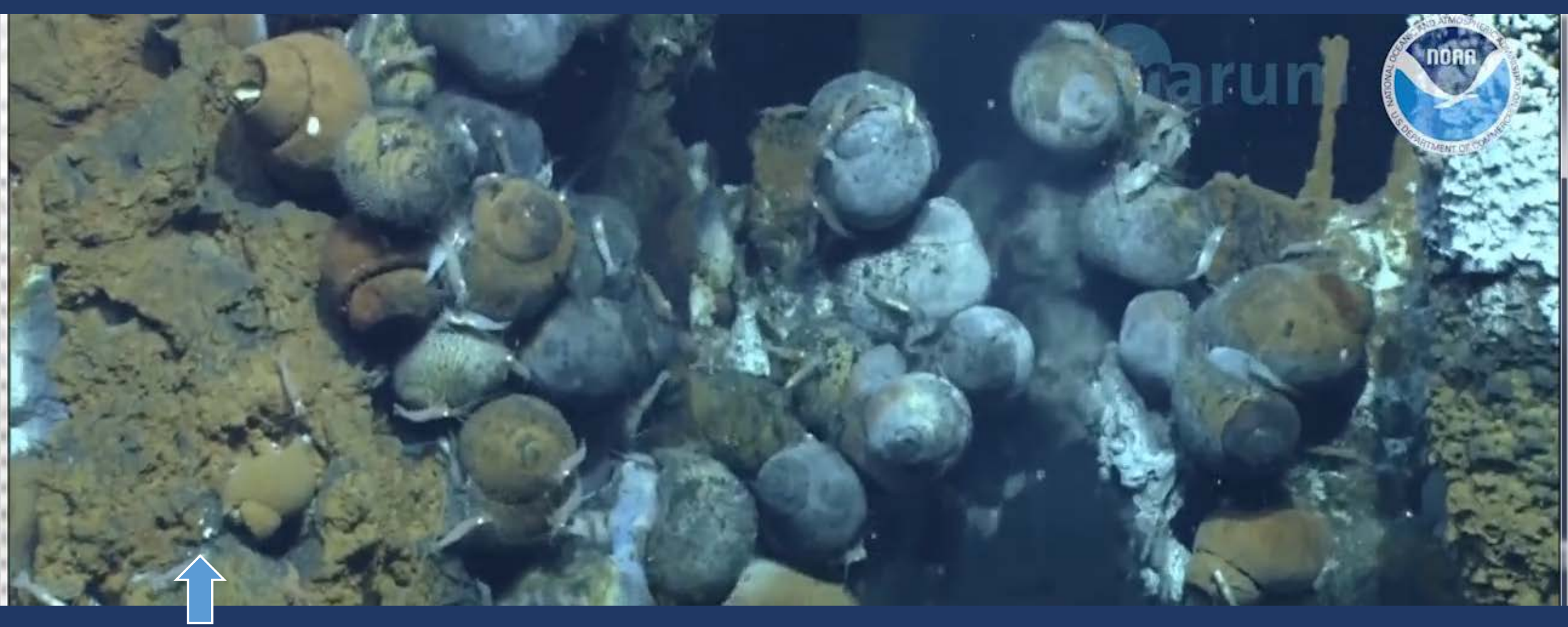

Note: Niua South is in Tonga EEZ 
Potential trade-offs in use vs. non-use values: mineral resource vs. existence value

Example for cultural services:

Ecologically or Biologically Significant Areas (EBSAs)
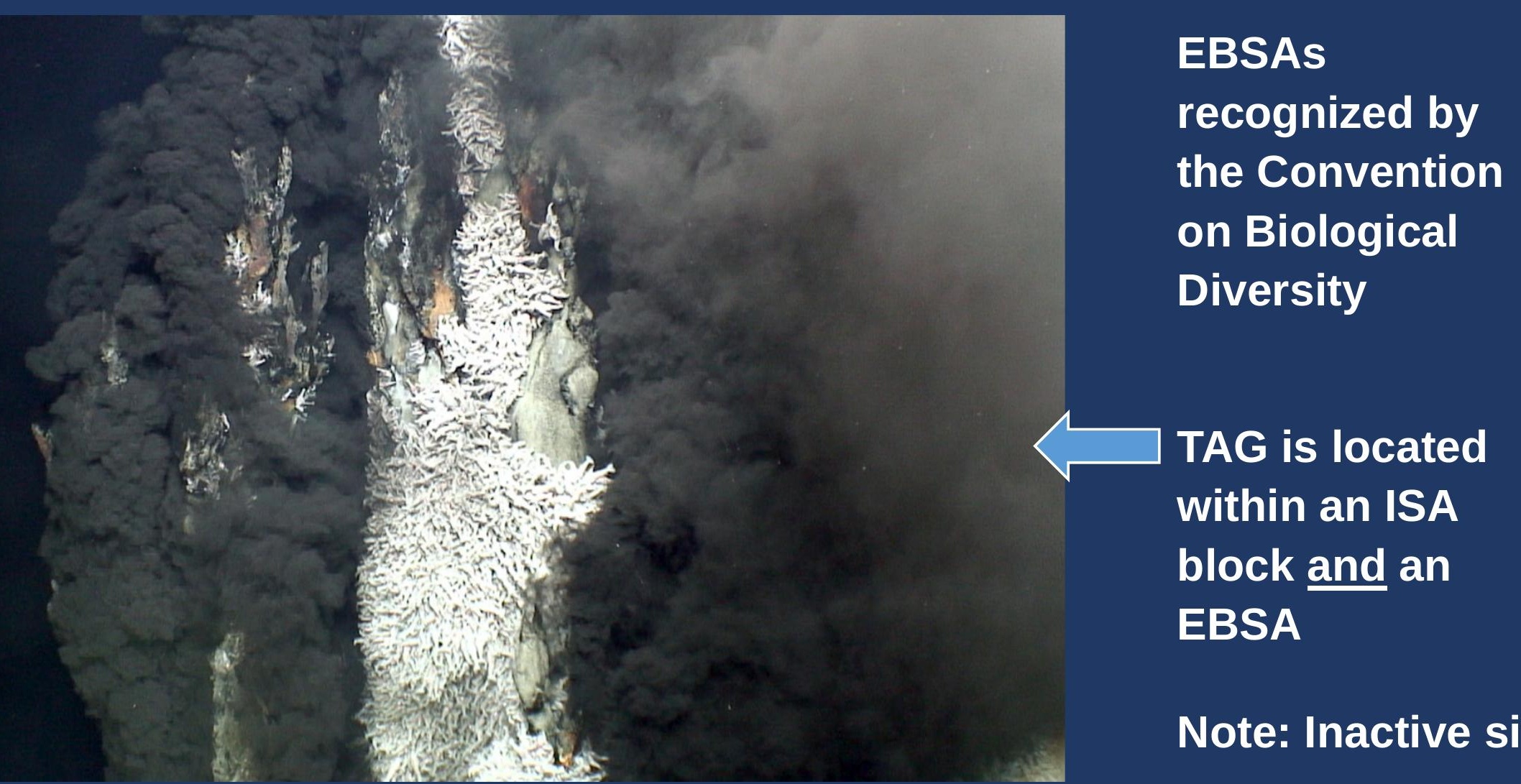

Note: Inactive sites 


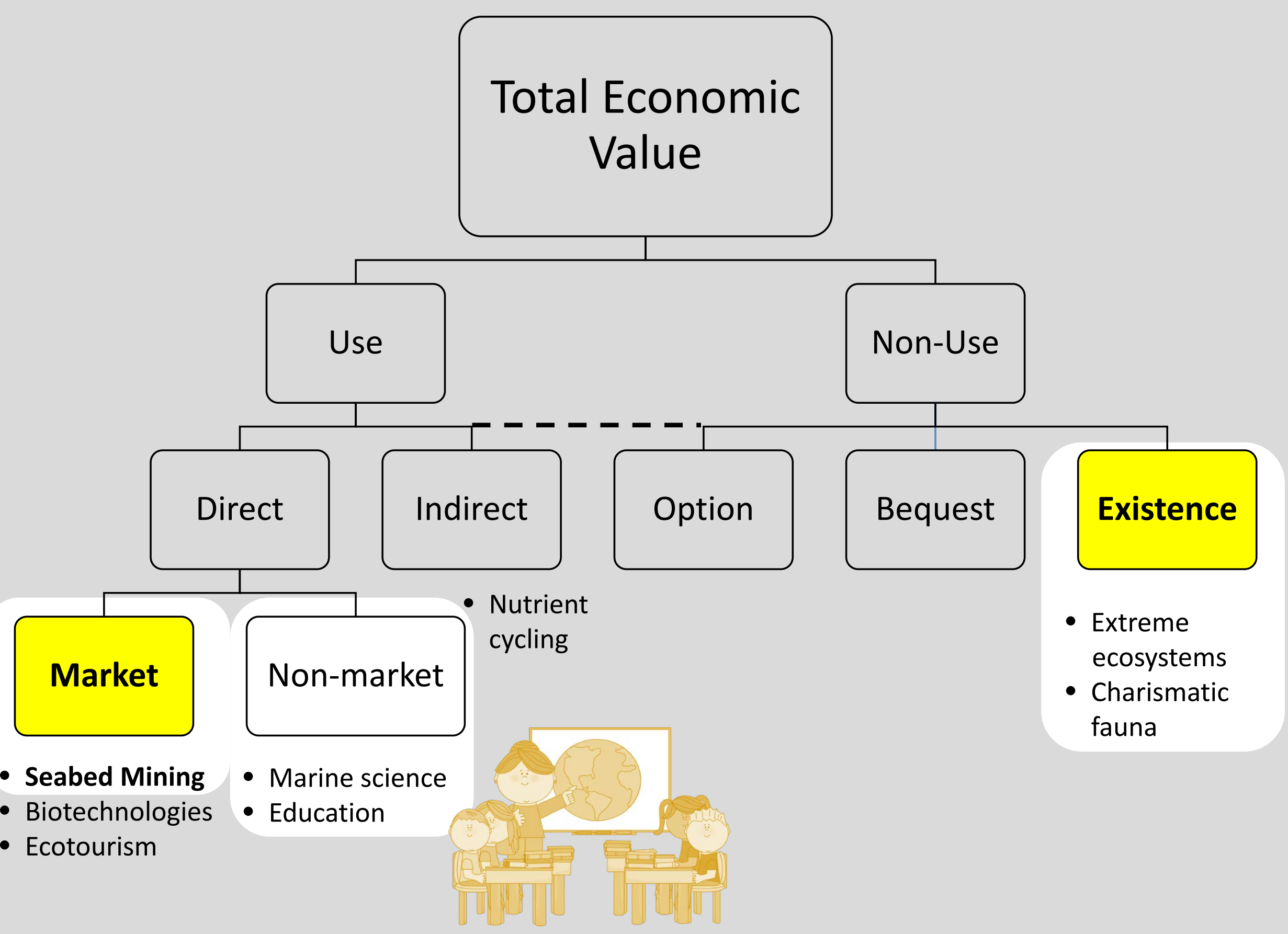




\section{Societal values of Marine Protected Areas}

\section{Marine Protected Areas can preserve non-use values \\ (and use values, as well, in the case of Ecotourism)}
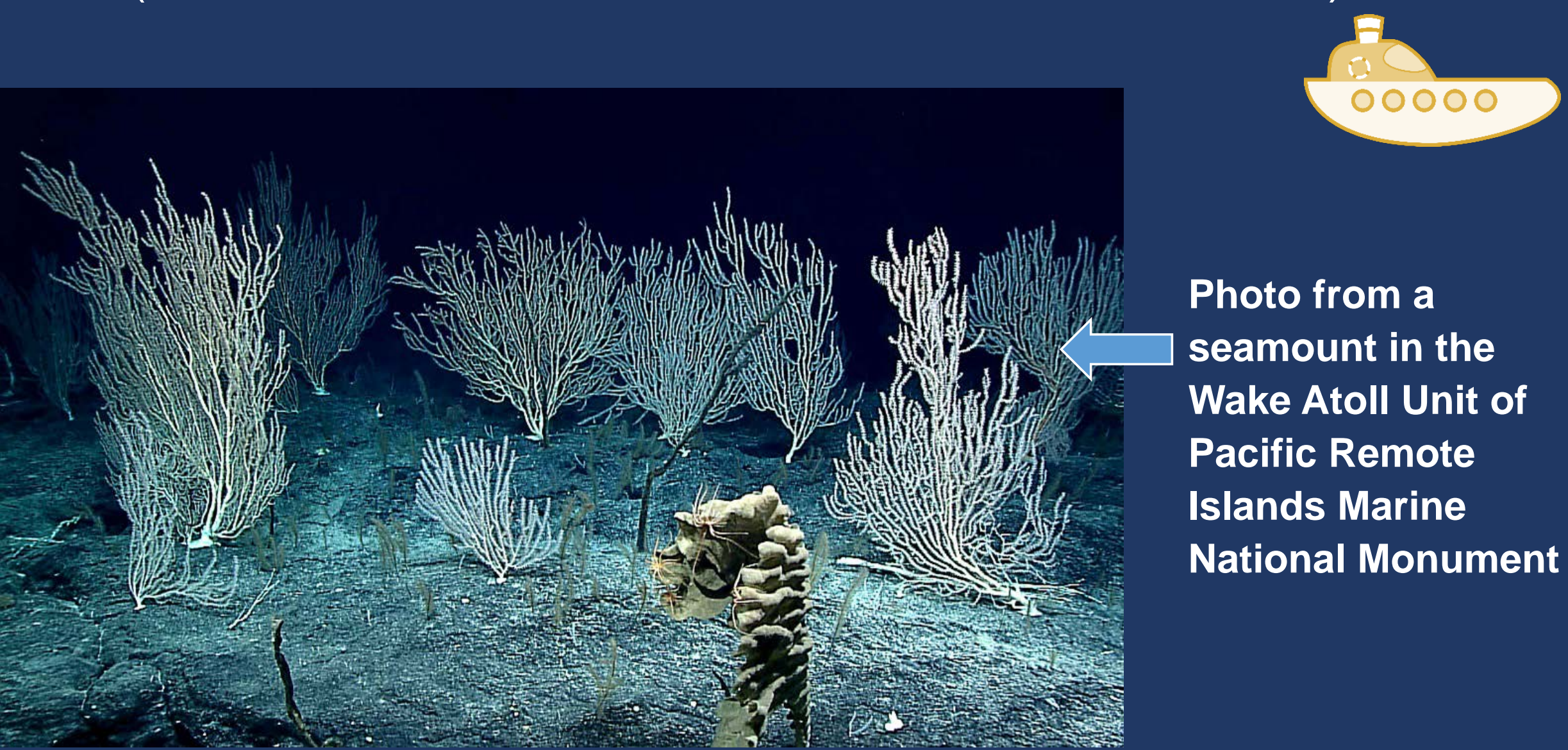

Photo from a seamount in the Wake Atoll Unit of Pacific Remote Islands Marine National Monument 
What new research do we need to answer: What economic impacts do you anticipate?

Natural and social scientists need to work together to assess use and non-use values of deep-sea ecosystems.

Biogeochemistry + Economics + Sociology
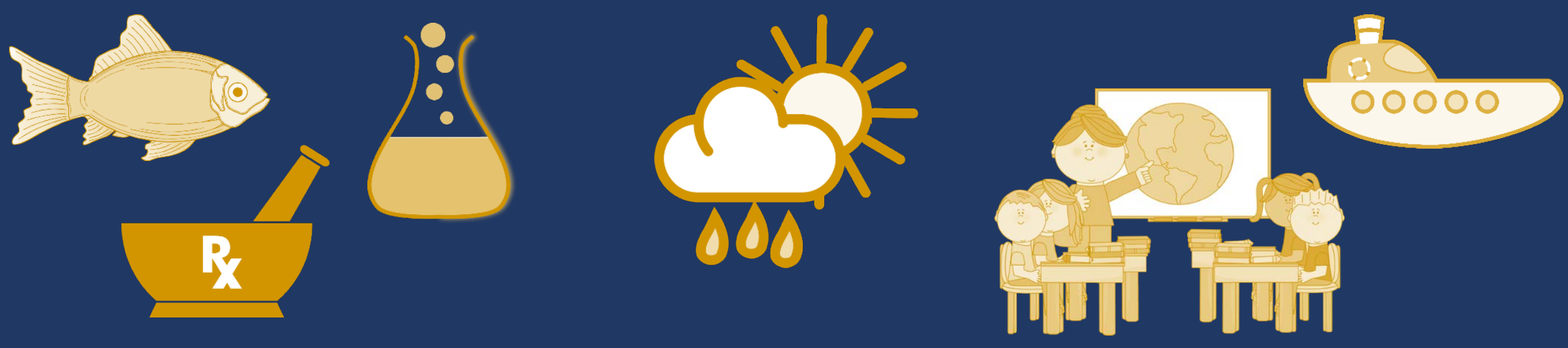


\section{AAAS 2017 Theme: Serving Society Through Science Policy}

How could this science inform policy?

For areas beyond national jurisdiction:

a new international legal instrument under UNCLOS for the conservation and sustainable use of marine biodiversity is

being developed by a Preparatory Committee

trade-offs in use vs. non-use values for biological resources

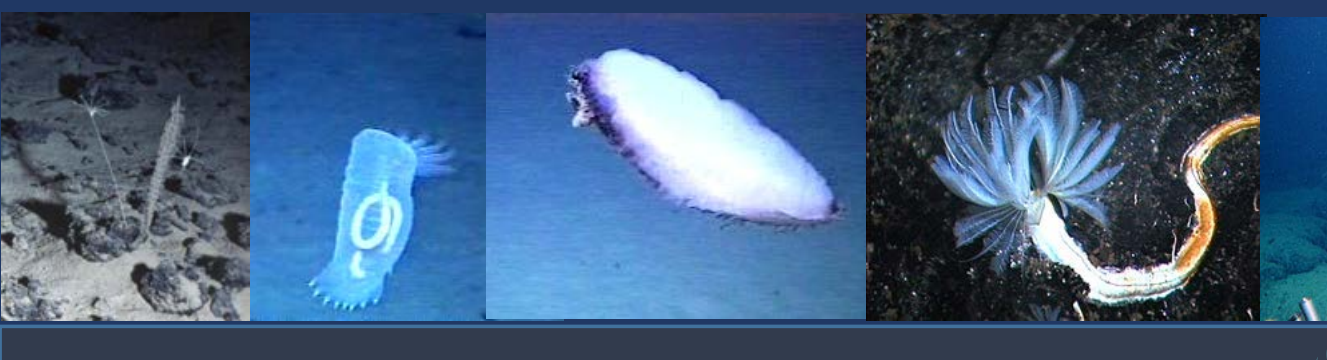

Yale

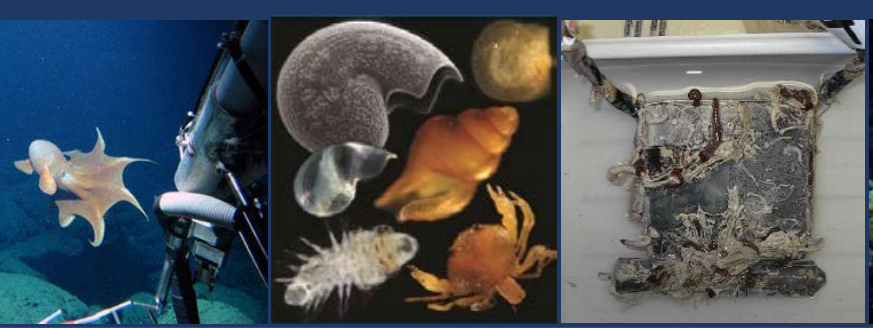

Woods Hole
Oceanographic 


\section{Should We Mine the Seafloor?}

In these talks, we provide information for your own decisions.

\section{My goal: to provide the best available, objective, scientific evidence to inform policy.}

Today's session is timely:

- ISA regulations: Next meeting starts Monday (Feb. 20)

- New UNCLOS instrument: Meeting next month (Mar. 27)

Also see: Science, Policy Forum, February 3, 2017 


\section{Co-Pls and funding:}

- Porter Hoagland, Chris German, and Maurice Tivey at WHOI, "Assessing the values of ecosystem services at deep-sea hydrothermal vents," funded by The Joint Initiative Awards Fund from the Andrew W. Mellon Foundation

- Lauren Mullineaux and Michael Neubert at WHOI, "Metacommunity Dynamics at Hydrothermal Vents," funded by the National Science Foundation \#1558904

and "Effects of Disturbance and Larval Supply on Communities at Hydrothermal Vents," funded by the National Science Foundation \#1356738
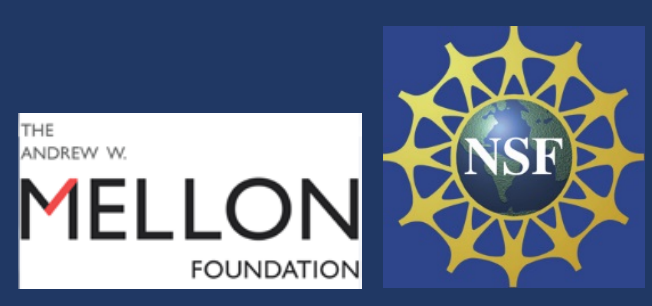


\section{Additional acknowledgments:}

- Teresa Radziejewska, University of Szczecin, Poland, funded by National Science Centre (Poland) and JPI Oceans Pilot Action "Ecological Aspects of Deep-Sea Mining"

- Christopher Kelley, University of Hawaii, Science Lead for NOAA Ship Okeanos Explorer, Deepwater Wonders of Wake cruise, funded by NOAA Office of Ocean Exploration and Research

- NOAA PMEL Earth-Ocean Interactions: Joe Resing, Bill Chadwick

- Oregon State University, Dept. Pharmaceutical Sciences: Kerry McPhail

- GEOMAR Kommunikation und Medien: Sarah Kaehlert

- WHOI NDSF: Scott McCue, for TAG video, credit: George Luther, Univ. Delaware/NSF/ROV Jason 2012 @Woods Hole Oceanographic Institution

- WHOI Communications including Graphic Services: Tim Silva 